\title{
OBSERVED EXPECTATIONS, NEWS SHOCKS, AND THE BUSINESS CYCLE
}

\author{
FABIO MILANI \& ASHISH RAJBHANDARI \\ University of CALIFORNiA, IRVINE
}

\begin{abstract}
This paper exploits information from the term structure of survey expectations to identify news shocks in a a DSE model with rational expectations.

We estimate a structural business-cycle model with price and wage stickiness. We allow for both unanticipated and anticipated components ("news") in each structural disturbance: neutral and investment-specific technology shocks, government spending shocks, risk premium, price and wage markup shocks, and monetary policy shocks.

We show that the estimation of a standard DSGE model with realized data obfuscates the identification of news shocks and yields weakly or non-identified parameters pertaining to such shocks. The identification of news shocks greatly improves when we re-estimate the model using data on observed expectations regarding future output, consumption, investment, government spending, inflation, and interest rates - at horizons ranging from one-period to five-periods ahead.

The news series thus obtained largely differ from their counterparts that are estimated using only data on realized variables. Moreover, the results suggest that the identified news shocks explain a sizable portion of aggregate fluctuations. News about investment-specific technology and risk premium shocks play the largest role, followed by news about labor supply (wage markup) and monetary policy.
\end{abstract}

Keywords: News Shocks, Estimation of DSGE Model with Survey Expectations, News in Business Cycles, Identification in DSGE Models, Rational Expectations.

JEL classification: E32, E50.

Date: October, 2012.

Address for correspondence:

Fabio Milani: Department of Economics, 3151 Social Science Plaza, University of California, Irvine, CA 92697-5100. Phone: 949-824-4519. Fax: 949-824-2182. E-mail: fmilani@uci.edu. URL: http://www.socsci.uci.edu/ $\sim$ fmilani. Ashish Rajbhandari: Department of Economics, 3151 Social Science Plaza, University of California, Irvine, CA 92697-5100. Phone: 949-824-5788. Fax: 949-824-2182. E-mail: arajbhan@uci.edu. 


\section{INTRODUCTION}

The key role of expectations in driving or amplifying aggregate economic fluctuations was recognized a long time ago. Pigou (1927) pointed to excesses of optimism and pessimism by businessmen as causes of fluctuations in economic activity. Keynes (1936) attributed a large portion of fluctuations to the action of investors' animal spirits. A renowned survey of business cycle theories written in the 1930s by Haberler (1937) also assigned a central role to expectations, including discussions of how expectations may represent sources of shocks to the economy.

With the rational expectations revolution in the 1970s, however, the function of expectations in macroeconomic models has changed. Expectations still remain key in the propagation of macroeconomic shocks. But under the assumption of rational expectations, expectations generally no longer constitute autonomous sources of fluctuations. ${ }^{1}$ Expectational errors can be expressed as unique functions of structural innovations. The majority of macroeconomic models with rational expectations, therefore, abstracts from expectation shocks that cannot be explicitly reconducted to fundamentals. The most popular contemporaneous theories of the business cycle imply that fluctuations are driven by unanticipated fundamental shocks, most often to technology (Hicks-neutral or investment-specific) or to demand conditions (such as preference shocks that affect consumers's utility, exogenous shifts in government spending, and so forth).

Theories of expectations-driven business cycles, however, have attracted much renewed attention recently. On the theoretical side, Beaudry and Portier (2006) and Jaimovich and Rebelo (2009) present models in which news about future technology shocks is a primary source of business cycle fluctuations, leading to comovement in output, consumption, investment, and labor hours. These theories imply that news about the future is able to generate realistic boom-bust cycles even if no change in technology materializes ex-post. ${ }^{2}$

Recently, the interest has turned toward evaluating empirically theories based on news and quantifying the contribution of news to aggregate fluctuations. Beaudry and Portier (2006) are the first to provide favorable empirical evidence in the context of structural VARs. They show that a shock that doesn't affect technology in the short-run, but that is correlated with technology in the long-run, accounts for a large share of fluctuations. Given its properties, the shock can be interpreted as reflecting news about future technology. Beaudry and Lucke (2010) find similar evidence using more comprehensive VAR and VECM specifications, including a variety of identified shocks.

\footnotetext{
${ }^{1}$ An exception is the literature on sunspots, equilibrium indeterminacy, and animal spirits, in rational expectations models (e.g., Benhabib and Farmer, 1999). In such cases, expectational errors depend not only on fundamental innovations, but also on sunspots shocks, which are unrelated to fundamentals. Sunspot shocks can induce fluctuations and increase volatility in such models.

${ }^{2}$ Lorenzoni (2011) presents a review of the mechanisms at work in microfounded business cycle models with news.
} 
Another strategy to investigate the importance of news consists of utilizing fully-fledged structural models as opposed to atheoretical VARs. Schmitt-Grohé and Uribe (2012) estimate a DSGE model with flexible prices, which incorporates news about future neutral and investment-specific technology, preference, government spending, and wage mark-up shocks, and conclude that news accounts for roughly half of output movements. Other papers, however, follow similar strategies to estimate DSGE models that are extended to include sticky prices, sticky wages, and a larger menu of structural disturbances (e.g., Fujiwara et al., 2011, Khan and Tsoukalas, 2012), but find only a modest role for news.

The wide range of results is not necessarily surprising. The identification of what should be defined as news from macroeconomic data is complicated. The structural shocks that enter business cycle models are already unobserved to the econometrician. When news is added, both the unanticipated and the anticipated (the news) components in the structural shocks are treated as unobserved and need to be inferred from a typically limited set of macroeconomic time series. The separation of the two components rests on the property that news affects future expectations of the structural shocks, which in turn affect consumption, investment, price setting, and other optimizing decisions, while unanticipated components do not influence future forecasts.

Empirical papers on news, however, typically do not have available or do not employ information on private sector's anticipations. VAR studies use stock prices as a proxy forward-looking variable that is meant to capture news about future technology. Other forward-looking variables have also been used (e.g., consumer confidence, slope of the term structure) with mixed conclusions. DSGE models, instead, have lagged behind in the use of similar forward-looking variables (with stock prices being a partial exception, since they are occasionally used in robustness check exercises as an additional observable).

Paper's Contribution. This paper aims to advance the empirical literature on the importance of news in business cycles by exploiting the extensive, but underused, information contained on the available observed expectations data. We exploit the term structure of expectations, obtained from the Survey of Professional Forecasters, in the estimation of a DSGE model, while retaining the conventional assumption of rational expectations. Observed expectations provide additional key information that can constrain the computation of rational expectations through additional measurement equations that are appended to the model, and that can help the econometrician disentangle unanticipated shocks and news over the business cycle.

We estimate a popular DSGE model with sticky prices and wages, based on Smets and Wouters (2007), using full-information Bayesian methods. We exploit expectations at the one, two, three, four, and five-quarter-ahead horizons on output, consumption, investment, government spending, 
inflation, and interest rates, to inform the extraction of news shocks. Given our focus on the identification of news over the sample, we find it worthwhile using real-time data for our macroeconomic series of interest in the estimation. We show, however, that the conclusions are robust to the use of revised, current-vintage, data series.

In terms of methodological choices, we believe that an advantage of our approach is that it can fully retain the assumption of rational expectations, yet it forces expectations to be consistent with the available observed expectation series. Even under the assumption of rational expectations, expectations-driven business cycles may arise here because of the existence of news. News about future shocks, and subsequent revisions in those news, can constitute a source of aggregate fluctuations and create additional volatility in the economic system.

In addition, the use of a structural theory-based model, rather than a VAR, is motivated, among other things, by the well-known invertibility problem that affects VARs when anticipations are present (e.g., Leeper and Walker, 2008). Leeper and Walker discuss how the different information sets available to the agents in the economy and to the econometrician estimating the VAR, which exist when anticipations are an important component of the data, prevent econometricians from correctly identifying the structural shocks, and consequently lead to misleading impulse responses and variance decomposition shares.

In our empirical analysis, we compare the news shocks and their importance for business cycles with those estimated without using any information from expectations. We also re-estimate the model without news and with revised, rather than real-time, data to check the contribution of each modeling and estimation element to the final results.

When the model is estimated omitting data on expectations, it is unclear whether news shocks actually play a major role in the economy. First, the posterior means of the standard deviations of news shocks move closer to zero if compared with the corresponding prior means. The vast majority of the $95 \%$ credible sets for the news parameters contain the value of zero, which would indicate that the specific news is empirically unimportant. The main finding, however, is that, when expectations data are not used in the estimation, several parameters related to news shocks are very weakly identified or non-identified. In many cases, the priors are not really updated, as the posterior distributions for the news standard deviations overlap with the priors, or, if not overlapping, the two distributions closely resemble each other.

When the model is re-estimated exploiting data on observed expectations, the identification of news substantially improves. The posterior distributions for the news coefficients now typically fall further from the priors, and become narrower around their means. Moreover, the data often 
suggest values for the standard deviations of news that are significantly higher than prior means; in most cases, the credible sets are in strictly positive range.

In the baseline estimation, the empirical results indicate (unanticipated) investment-specific technology shocks as the main drivers of business cycles, a finding that is in line with recent evidence by Justiniano, Primiceri, and Tambalotti (2011), among others. Such shocks explain between 30 and $40 \%$ of real GDP growth (forecast error) variance. But news shocks are also important: the fraction of aggregate economic fluctuations that can be attributed to news also falls between 30 and $40 \%$. News about the investment-specific technology shock at short-term horizons accounts for the largest share; short-term news about monetary policy and longer-horizon news about the risk-premium and wage markup shocks also have nontrivial roles.

The inclusion of expectations and news in the estimation also leads to changes in the posterior estimates for coefficients that are unrelated to news. The degree of real frictions, such as habit formation in consumption and investment adjustment costs, substantially falls. The degree of nominal frictions, such as rigidity in wages and prices, and indexation to past inflation, are also reduced. Therefore, the evidence suggests that news and subjective expectations work to create persistence in the system, so that the role of some popular frictions is diminished.

Related Literature. The paper mainly aims to add to the emerging literature focused on testing the empirical importance of news over the business cycle. While the previously-discussed results by Beaudry and Portier (2006) and Beaudry and Lucke (2009) suggest a major role for news in VAR models, others (e.g., Forni et al., 2011, using a factor-augmented VAR) disagree. Theoretical work and the early empirical papers have mostly focused on news about technology. Schmitt-Grohé and Uribe (2012) estimate a RBC-type model and allow for news in a wider range of disturbances. Fujiwara et al. (2011), Khan and Tsoukalas (2012), estimate DSGE models with New Keynesian features similar to the one we use here. Again, there is contrasting evidence. SchmittGrohé and Uribe (2012) uncover a significant role of news over the business cycle. Fujiwara et al. (2011) and Khan and Tsoukalas (2012), on the other hand, find only limited contributions. Milani and Treadwell (2012) consider news regarding future monetary policy choices, possibly indicating central bank announcements or simply private sector's attempts at anticipations, and show that anticipated monetary policy innovations play a larger role over the business cycle than monetary policy surprises. Rajbhandari (2012) estimates an open economy model with news and finds a limited transmission of news across countries, while news plays an important role domestically.

Within the literature on estimated DSGE models with news, this paper has also points of contact with Adrjiev (2011), who suggests using stock prices in the estimation of DSGE models with news to better capture forward-looking information. Our paper differs, because we use an extensive set of 
expectations, directly regarding most variables that enter the model. Adrjiev studies the effects of adding stock prices in different estimated specifications of a flexible price model, while we consider a possibly more conventional sticky-price sticky-wage model of the U.S. economy. Moreover, our use of expectations about a large set of macroeconomic variables, rather than a stock price index as a single forward-looking variable, has the advantage of shielding us from the well known difficulty of general equilibrium models to simultaneously explain the real and financial sides of the economy. The results in the two papers, however, can usefully complement each other. ${ }^{3}$

In terms of methodology, the paper shows how the inclusion of expectations data can be useful to prevent rational expectations from falling too far from the available observations on macroeconomic expectations. The approach used here, therefore, is not restricted to applications focused on news, but it can be generally exploited in the estimation of any DSGE model, with or without rational expectations. ${ }^{4}$

There is a long history of interest in the use of survey data on expectations (as exemplified, for example, by the survey by Pesaran and Weale, 2006). But their use in the estimation of DSGE models has started only more recently. Del Negro and Eusepi (2011) question whether typical models with rational expectations can match the dynamics of observed inflation expectations. Ormeno (2011) uses inflation expectations data in the estimation of a model with learning. Milani (2011) uses data on observed output, inflation, and interest rate expectations in a model with learning, showing that identified expectation shocks account for roughly half of U.S. business cycle fluctuations; Milani (2012b) extends the analysis to a medium-scale model. This paper, instead, uses a much larger set of expectations data than those precursors, and its novelty lies in exploiting them to instruct the extraction of news.

\section{Model Framework}

2.1. A Sticky-Price Sticky-Wage DSGE Model. We use a popular medium-scale DSGE model, based on Smets and Wouters (2007) and Christiano et al (2005), to characterize the dynamics of the U.S. economy at business cycle frequencies.

The model includes a number of real and nominal rigidities, which have been shown to be useful in fitting macroeconomic time series. Prices and nominal wages are sticky à la Calvo. Capital

\footnotetext{
${ }^{3}$ A contemporaneous paper, which has evolved entirely independently from our work, by Hirose et al (2012) has similar scopes to ours. They estimate a small-scale three-equation New Keynesian model using forecasts' data from the Survey of Professional Forecasters. We focus on a more conventional, larger-scale, business cycle model of the U.S. economy and we exploit a much larger set of expectations series, which allow us to better extract and disentangle news about technology, risk-premia, markup-shocks, and so forth. There are also differences in some of the econometric choices, which will be discussed later in the paper. Again, the results in the two papers can usefully complement and reinforce each other.

${ }^{4}$ The use of survey expectations to inform and constrain the estimation of rational expectations models has been advocated, for example, in Milani (2012a) and Milani and Rajbhandari (2012).
} 
adjustment decisions are subject to adjustment costs and the capacity utilization rate can be varied depending on the rental rate of capital. Consumers are assumed to maximize a utility function that is non-separable in consumption (subject to external habit formation) and labor. The model is consistent with a balanced steady-state growth path driven by a deterministic rate of progress in technology.

The log-linearized model equations are as follows ${ }^{5}$

$$
\begin{aligned}
y_{t} & =c_{y} c_{t}+i_{y} i_{t}+u_{y} u_{t}+g_{y} g_{t} \\
c_{t} & =c_{1} c_{t-1}+\left(1-c_{1}\right) E_{t} c_{t+1}+c_{2}\left(l_{t}-E_{t} l_{t+1}\right)-c_{3}\left(r_{t}-E_{t} \pi_{t+1}+b_{t}\right) \\
i_{t} & =i_{1} i_{t-1}+\left(1-i_{1}\right) E_{t} i_{t+1}+i_{2} q_{t}+\phi_{t} \\
q_{t} & =q_{1} E_{t} q_{t+1}+\left(1-q_{1}\right) E_{t} r_{t+1}^{k}-\left(r_{t}-E_{t} \pi_{t+1}+b_{t}\right) \\
y_{t} & =\Phi_{p}\left(\alpha k_{t}^{s}+(1-\alpha) l_{t}+a_{t}\right) \\
k_{t}^{s} & =k_{t-1}+u_{t} \\
u_{t} & =u_{1} r_{t}^{k} \\
k_{t} & =k_{1} k_{t-1}+\left(1-k_{1}\right) i_{t}+k_{2} \phi_{t}^{i} \\
\mu_{t}^{p} & =\alpha\left(k_{t}^{s}-l_{t}\right)+a_{t}-w_{t} \\
\pi_{t} & =\pi_{1} \pi_{t-1}+\pi_{2} E_{t} \pi_{t+1}-\pi_{3} \mu_{t}^{p}+\nu_{t}^{p} \\
r_{t}^{k} & =-\left(k_{t}-l_{t}\right)+w_{t} \\
\mu_{t}^{w} & =w_{t}-\left(\sigma_{l} l_{t}+\frac{1}{1-h / \gamma}\left(c_{t}-\frac{h}{\gamma} c_{t-1}\right)\right) \\
w_{t} & =w_{1} w_{t-1}+\left(1-w_{1}\right) E_{t}\left(w_{t+1}+\pi_{t+1}\right)-w_{2} \pi_{t}+w_{3} \pi_{t-1}-w_{4} \mu_{t}^{w}+\nu_{t}^{w} \\
R_{t} & =\rho_{R} R_{t-1}+\left(1-\rho_{R}\right)\left[r_{\pi} \pi_{t}+r_{y}\left(y_{t}-y_{t}^{*}\right)+r_{\Delta y}\left(\Delta y_{t}-\Delta y_{t}^{*}\right)\right]+m p_{t} .
\end{aligned}
$$

The composite coefficients in the previous equations are given by:

$$
\begin{array}{lll}
c_{y}=1-i_{y}-g_{y} ; & i_{y}=\delta k_{y} ; & u_{y}=r_{k}^{*} k_{y} ; \\
c_{1}=h /(1+h) ; & c_{2}=\left(\sigma_{c}-1\right)\left(W_{*}^{h} L_{*} / C_{*}\right) / \sigma_{c}(1+h) ; & c_{3}=(1-h) /\left[\sigma_{c}(1+h)\right] ; \\
i_{1}=1 /(1+\beta) ; & i_{2}=1 /[(1+\beta) \varphi] ; & \\
q_{1}=\beta(1-\delta) ; & & \\
u_{1}=\psi /(1+\psi) ; & & \\
k_{1}=1-\delta ; & k_{2}=\delta(1+\beta) \varphi ; & \\
\pi_{1}=\iota_{p} /\left(1+\beta \iota_{p}\right) ; & \pi_{2}=\beta /\left(1+\beta \iota_{p}\right) ; & \\
\pi_{3}=\left[1 /\left(1+\beta \iota_{p}\right)\right]\left[\left(1-\beta \xi_{p}\right)\left(1-\xi_{p}\right) /\left(\xi_{p}\left(\phi_{p}-1\right) \varepsilon_{p}+1\right)\right] ; & \\
w_{1}=1 /(1+\beta) ; & w_{2}=\left(1+\beta \iota_{w}\right) /(1+\beta) ; & \\
w_{4}=[1 /(1+\beta)]\left[\left(1-\beta \xi_{w}\right)\left(1-\xi_{w}\right) /\left(\xi_{w}\left(\phi_{w}-1\right) \varepsilon_{w}+1\right)\right] . &
\end{array}
$$

Equation (2.1) is the economy's aggregate resource constraint. Output, denoted by $y_{t}$, equals the sum of consumption $c_{t}$, investment $i_{t}$, government spending $g_{t}$, and the resource cost of varying

\footnotetext{
${ }^{5}$ For the interested reader, a detailed derivation of the model equations is available in a technical appendix as supplement to Smets and Wouters (2007), and hence not repeated here.
} 
capital utilization, where $u_{t}$ is the capital utilization rate. The parameters $c_{y}, i_{y}, g_{y}$, denote the shares of consumption, investment (which, in turn, is a function of the capital depreciation rate $\delta$ and of the capital-to-output ratio $k_{y}$ ), and government spending, to output, in steady-state, and $u_{y}$ denotes the steady-state rate of capital utilization, which depends on the steady-state rental rate of capital $r_{k}^{*}$ and capital-to-output ratio.

Equation (2.2) is the log-linearized consumption Euler equation. Current consumption depends on both past consumption, through the assumption of external habit formation in the utility function, and expectations about future consumption, on current and expected labor supply, where $l_{t}$ denotes hours of work, and on the ex-ante real interest rate $\left(i_{t}-E_{t} \pi_{t+1}\right)$. Consumption is also affected by a disturbance $b_{t}$, which is a risk-premium shock. The composite coefficients $c_{1}, c_{2}$, and $c_{3}$ are functions of the structural parameters $0 \leq h \leq 1$, which denotes the degree of habit formation, $\sigma_{c}>0$, the inverse of the elasticity of intertemporal substitution, $\sigma_{l}>0$, the inverse of the Frisch elasticity of labor supply, and $\gamma$, the economy's steady-state growth rate, as well as of the steady-state levels of wages, hours, and consumption.

Equation (2.3) describes the dynamics of investment. Current investment $i_{t}$ depends on lagged investment, which enters through the assumption of adjustment costs related to changes in the rate of investment, expected future investment, and on the real value of the capital stock $q_{t}$. The sensitivity of investment to $q_{t}$ is an inverse function of the elasticity of the cost of capital adjustment $\varphi$ in the capital adjustment function; the coefficient $\beta$ denotes, instead, the household's discount factor. The term $\phi_{t}$ denotes an investment-specific technology shock.

The value of the capital stock evolves as indicated by equation (2.4). The current value is affected by future expectations for the value of capital, future expectations for the rental rate $r_{t}^{k}$, and by the ex-ante real interest rate. The risk-premium shock also enters the equation for $q_{t}$, helping the model account for the comovement between consumption and investment.

Equation (2.5) denotes the aggregate production function. Capital services $k_{t}^{s}$ and labor $l_{t}$ are used to produce output. The term $a_{t}$ is the total factor productivity shock. The parameter $\Phi_{p}$ is equal to one plus the fraction of fixed costs in production, while $\alpha$ denotes the share of capital.

Equation (2.6) expresses capital services as a function of the past capital stock $k_{t-1}$ and the utilization rate. The capital utilization rate is a function of the rental rate of capital, as indicated by Equation (2.7). The parameter $u_{1}$ is an inverse function of the elasticity of the capital utilization adjustment cost function, which is governed by parameter $\psi$.

Equation (2.8) describes the capital accumulation process. Capital is expressed as a function of the past capital stock, current investment, and is affected by the investment-specific technology shock. 
Equation (2.9) expresses the price markup as the difference between the marginal product of labor and the real wage. The price markup is a driver of inflation. Inflation dynamics is characterized by equation (2.10), which is a New Keynesian Phillips curve. Current inflation depends on lagged inflation, through the assumption of indexation to past inflation in price setting, expected inflation, on the price markup, and on a price markup shock $\nu_{t}^{p}$. The degree of backward-lookingness in inflation is a positive function of $0 \leq \iota_{p} \leq 1$, the degree of automatic price indexation, while the slope of the curve is an inverse function of the degree of price stickiness, which depends on the Calvo parameter $\xi_{p}$; other coefficients that affect the slope are $\phi_{p}$ and $\epsilon_{p}$, the steady-state price markup and the curvature of the Kimball aggregator function.

Equation (2.11) expresses the rental rate of capital as a positive function of the real wage and a negative function of the capital-labor ratio. In equation (2.12), the wage markup is expressed as equal to the difference between the real wage and the marginal rate of substitution between consumption and leisure. Equation (2.13) describes the evolution of the real wage, which depends on lagged wages, a term that arises from the assumption that nominal wages, when not re-optimized, are indexed to the past aggregate inflation rate, on the expected future real wage, on the wage markup, on past, current, and future inflation, and on the wage markup shock $\nu_{t}^{w}$. The reducedform parameters are a function of the degree of wage stickiness $\xi_{w}$, wage indexation to past inflation $\iota_{w}$, the discount factor, the steady-state wage markup $\phi_{w}$, and the Kimball curvature $\epsilon_{w}$.

Finally, it is common to assume that monetary policy can be approximated by a Taylor rule as in equation (2.14). The policy instrument is partially adjusted depending on movements in the levels of inflation and the output gap, and in the growth rate of the output gap. The output gap is defined as the deviation of output from its potential level $y_{t}^{*}$, where potential output is denoted as the level of output that would prevail in the same economy, but under flexible prices and wages (and no markup shocks). Deviations from systematic monetary policy are captured by the monetary policy shock $m p_{t}$.

To highlight the importance of exploiting expectations in the estimation of models with news, we have chosen a DSGE model that serves as benchmark for much of the empirical macroeconomic literature. We have not altered preferences to limit the wealth effect on labor supply as in Jaimovich and Rebelo (2009) or Schmitt-Grohé and Uribe (2012). The change in preferences helps the model in capturing the comovement of macro variables, but, as discussed in Lorenzoni (2011), at the cost of generating positive income effects on labor supply (which are inconsistent with the micro evidence) or large increases in interest rates and plummeting asset prices after positive news shocks (which seem counterintuitive). We adopt a preference structure that is, instead, more standard for estimated DSGE models. It seems more natural, we believe, to introduce nominal rigidities, for 
which the micro evidence is more clearly favorable (e.g., Nakamura and Steinsson, 2008, for prices, and Barattieri et al, 2010, for wage rigidity), to obtain the necessary comovement over the business cycle conditional on a news shock.

2.2. Structural and News Shocks. We assume that expectations, denoted by the mathematical expectation operator $E_{t}$, are fully rational. We extend, however, the model to allow for anticipations regarding future shocks, i.e. news or news shocks. We assume that news can affect each disturbance in the model: it becomes an empirical matter to distinguish among those for which news matters, and those for which the introduction of news is superfluous.

There are seven exogenous disturbances: government spending $g_{t}$, risk-premium $b_{t}$, investmentspecific $\phi_{t}$, technology $a_{t}$, price markup $\nu_{t}^{p}$, wage markup $\nu_{t}^{p}$, and monetary policy $m p_{t}$. The shocks evolve as $\mathrm{AR}(1)$ processes (we assume also $\mathrm{AR}(1)$ markup shocks, which represent a minor difference from the $\operatorname{ARMA}(1,1)$ processes used in Smets and Wouters, 2007); as in Smets and Wouters (2007), we deal with the potential endogeneity of government spending by allowing it to respond to contemporaneous technology innovations. With the inclusion of news, now the disturbances' laws of motion become:

$$
\begin{aligned}
g_{t} & =\rho_{g} g_{t-1}+\varepsilon_{t}^{g}+g_{a}\left(\varepsilon_{t}^{a}+\sum_{h=1}^{H} \eta_{t-h}^{a, h}\right)+\sum_{h=1}^{H} \eta_{t-h}^{g, h} \\
b_{t} & =\rho_{b} b_{t-1}+\varepsilon_{t}^{b}+\sum_{h=1}^{H} \eta_{t-h}^{b, h} \\
\phi_{t} & =\rho_{\phi} \phi_{t-1}+\varepsilon_{t}^{\phi}+\sum_{h=1}^{H} \eta_{t-h}^{\phi, h} \\
a_{t} & =\rho_{a} a_{t-1}+\varepsilon_{t}^{a}+\sum_{h=1}^{H} \eta_{t-h}^{a, h} \\
\nu_{t}^{\pi} & =\rho_{\pi} \nu_{t-1}^{\pi}+\varepsilon_{t}^{\pi}+\sum_{h=1}^{H} \eta_{t-h}^{\pi, h} \\
\nu_{t}^{w} & =\rho_{w} \nu_{t-1}^{w}+\varepsilon_{t}^{w}+\sum_{h=1}^{H} \eta_{t-h}^{w, h} \\
m p_{t} & =\rho_{m p} m p_{t-1}+\varepsilon_{t}^{m p}+\sum_{h=1}^{H} \eta_{t-h}^{m p, h}
\end{aligned}
$$

where the terms $\eta_{t-h}^{j, h}$ denote news that becomes known in $t-h$ about shocks that materialize only $h$ periods ahead, and where $H$ is the maximum news horizon, which will be assumed equal to 5 in the baseline estimation, to match forecasts' data availability. Our horizon structure is, therefore, denser than the one in Schmitt-Grohé and Uribe (2012), who impose news at horizons 4 and 8 
only, but with the drawback that we do not include longer-term news. The terms $\varepsilon_{t}^{j}, j=g, \ldots, m p$, instead, denote the unanticipated shocks of type $j$ that are typically included in DSGE models.

The literature has more often emphasized news about future technology, as in (2.18), and recently also in the form of news about future investment-specific, rather than neutral, technology shocks, as in (2.17). But news regarding other disturbances, even related to demand, is equally plausible (Schmitt-Grohé and Uribe, 2012, and Khan and Tsoukalas, 2012, allow for news about a variety of supply and demand shocks). For example, news about government spending can allow researchers to capture the consequences of government announcements about spending or tax policy changes that will be implemented only at a future date. News about government spending has also been studied in Schmitt-Grohé and Uribe (2012), Khan and Tsoukalas (2012), and, in a SVAR context, in Mertens and Ravn (2011). In a similar way, allowing for news related to future monetary policy decisions yields a way to model the increasingly common central banks' announcements about the future direction of policy or, at least, to capture anticipations by the private sector about future central bank's decisions, whether correct or not (as analyzed in Milani and Treadwell, 2012). Here, we consider news about all seven disturbances. The scope is to let the data choose the nature of news that is more empirically relevant, rather than imposing dogmatic a priori restrictions. If some of the news shocks that are included aren't empirically relevant, they will end up being either unidentified or their standard deviations would settle around zero in the estimation.

As customary in the literature, all unanticipated and anticipated innovations are assumed to be independent. All innovations are i.i.d. and follow Normal distributions.

For each disturbance, assuming horizons $h=1,2,3,4,5$, news shocks are inserted in the state space model as follows (we present here the illustrative case for the monetary policy shock):

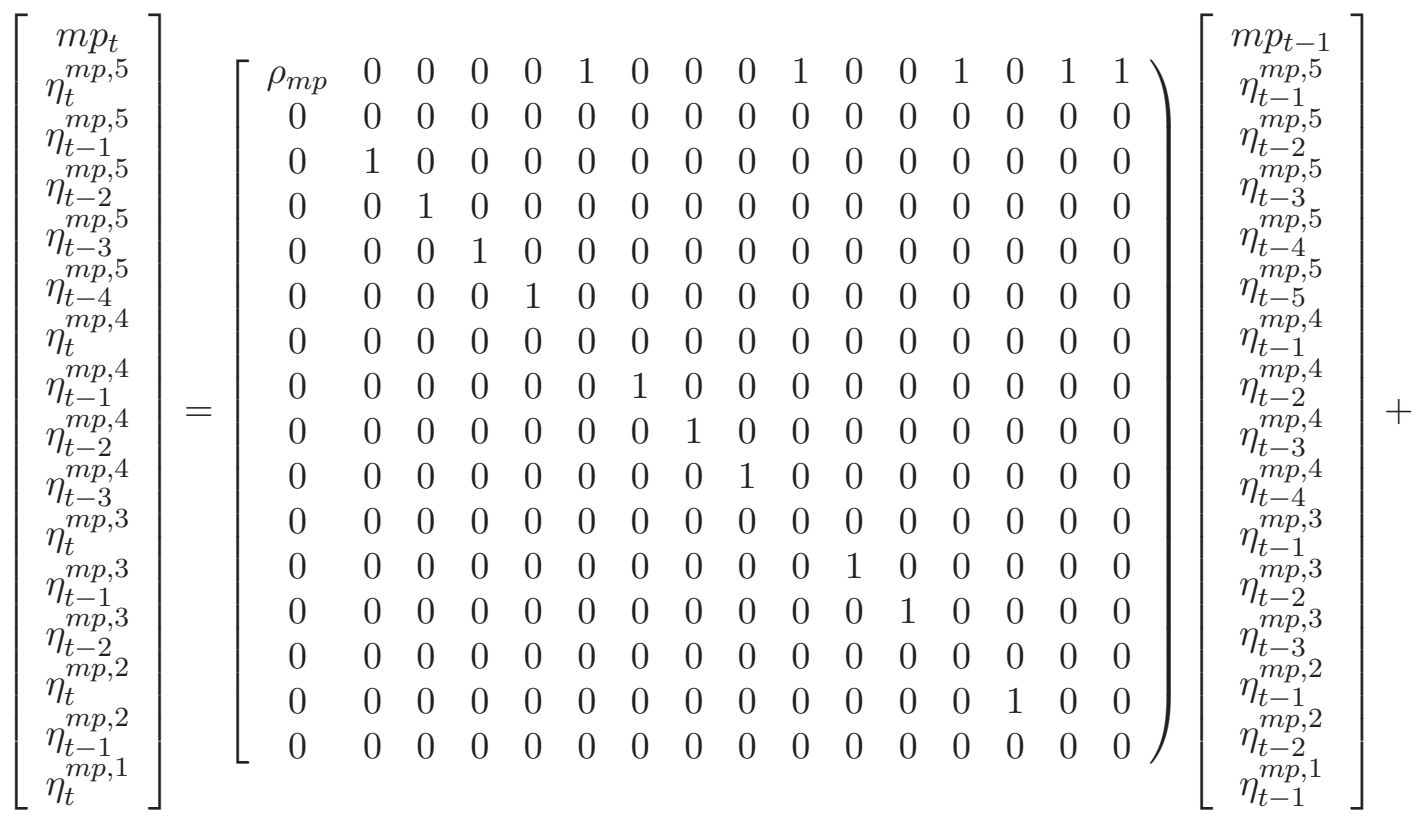




$$
+\left[\begin{array}{cccccccccccccccc}
\sigma_{m p} & 0 & 0 & 0 & 0 & 0 & 0 & 0 & 0 & 0 & 0 & 0 & 0 & 0 & 0 & 0 \\
0 & \sigma_{\eta_{m p, 5}} & 0 & 0 & 0 & 0 & 0 & 0 & 0 & 0 & 0 & 0 & 0 & 0 & 0 & 0 \\
0 & 0 & 0 & 0 & 0 & 0 & \sigma_{\eta_{m p, 4}} & 0 & 0 & 0 & 0 & 0 & 0 & 0 & 0 & 0 \\
0 & 0 & 0 & 0 & 0 & 0 & 0 & 0 & 0 & 0 & \sigma_{\eta_{m p, 3}} & 0 & 0 & 0 & 0 & 0 \\
0 & 0 & 0 & 0 & 0 & 0 & 0 & 0 & 0 & 0 & 0 & 0 & 0 & \sigma_{\eta_{m p, 2}} & 0 & 0 \\
0 & 0 & 0 & 0 & 0 & 0 & 0 & 0 & 0 & 0 & 0 & 0 & 0 & 0 & 0 & \sigma_{\eta_{m p, 1}}
\end{array}\right]^{\prime}\left(\begin{array}{c}
\varepsilon_{t}^{m p} \\
\tilde{\eta}_{t}^{m p, 5} \\
\tilde{\eta}_{t}^{m p, 4} \\
\tilde{\eta}_{t}^{m p, 3} \\
\tilde{\eta}_{t}^{m p, 2} \\
\tilde{\eta}_{t}^{m p, 1}
\end{array}\right)
$$

where the $\sigma$ coefficients denote standard deviations of the news shocks, and the $\tilde{\eta}$ terms simply redefine the original news denoted by $\eta$. Therefore, for each disturbance, the addition of news with horizons 1 to 5 , leads to an expansion of the state space dimension from 1 to 16 .

In DSGE models, the identification of news shocks works through their effects on expectations. News affects expectations about future structural disturbances, which, in turn, are relevant for expectations about future aggregate macroeconomic variables that are needed to solve households and firms' maximizing decisions. By construction, the structural innovations that are typically included in macroeconomic models are, instead, unpredictable and, hence, they do not affect future expectations. Expectations about future monetary policy shocks, for example, in the model with news equal

$$
E_{t}\left[\begin{array}{l}
m p_{t+1} \\
m p_{t+2} \\
m p_{t+3} \\
m p_{t+4} \\
m p_{t+5} \\
m p_{t+6}
\end{array}\right]=\left[\begin{array}{l}
\rho_{m p} m p_{t}+\eta_{t-4}^{m p+5}+\eta_{t-3}^{m p, 4}+\eta_{t-2}^{m p, 3}+\eta_{t-1}^{m p, 2}+\eta_{t}^{m p, 1} \\
\rho_{m p}^{2} m p_{t}+\eta_{t-3}^{m p, 5}+\eta_{t-2}^{m p, 4}+\eta_{t-1}^{m p, 3}+\eta_{t}^{m p, 2} \\
\rho_{m p}^{3} m p_{t}+\eta_{t-2}^{m p, 5}+\eta_{t-1}^{m p, 4}+\eta_{t}^{m p, 3} \\
\rho_{m p}^{4} m p_{t}+\eta_{t-1}^{m p, 5}+\eta_{t}^{m p, 4} \\
\rho_{m p}^{5} m p_{t}+\eta_{t}^{m p, 5} \\
\rho_{m p}^{6} m p_{t}
\end{array}\right]
$$

Therefore, expectations about one-period-ahead monetary policy deviations from the Taylor rule incorporate contemporaneous news, news obtained in the previous period, up to news obtained four periods in advance; two-quarter-ahead expectations are influenced by news that were obtained starting from three quarters in advance, and so forth, up to five-quarter-ahead expectations, which only incorporate contemporaneous news; expectations about six or more quarters ahead are unaffected by news in our framework.

In the empirical section, the identification of news regarding future monetary policy shocks will be informed, first and more directly, by the use of survey expectations about future short-term interest rates, but also by the use of all other observed expectations series. The identification will work in similar ways for news about other disturbances. Expectations will be used as observable variables that the estimation will try to match; the interaction between expectations and realized variables should provide additional restrictions that can be exploited to identify news.

Schmitt-Grohé and Uribe (2012) present Monte Carlo evidence showing that unanticipated and news shocks are identified in a stylized example. Identification, although theoretically possible, may not be straighforward in a complicated model as the one used here. We believe that using a variety of expectations series at different horizons will help the inference regarding news shocks. 
The news structure used in the paper can also account for revisions of previous private sector's anticipations (which may have failed to fully materialize). For example, economic agents receive in $t-5$ the news $\eta_{t-5}^{m p, 5}$ regarding a shock anticipated for time $t$. In $t-4$, the news shock $\eta_{t-4}^{m p}$ can be interpreted as a revision of the original news $\eta_{t-5}^{m p, 5}$ (since they both reflect information about shocks expected to materialize at time- $t$ ): the anticipation about future policy shocks is now given by $\left(\eta_{t-4}^{m p, 4}+\eta_{t-5}^{m p, 5}\right)$. In $t-3$, the term $\eta_{t-3}^{m p, 3}$, can be interpreted as a revision of the previous anticipation $\left(\eta_{t-4}^{m p, 4}+\eta_{t-5}^{m p, 5}\right)$, and so forth.

\section{Structural Estimation with Observed Expectations}

3.1. Observed Expectations and Real-Time Data. We estimate the DSGE model using fullinformation Bayesian methods. In the baseline estimation of the paper, we use real-time data, for a sample spanning the period between 1981:III and 2011:II (the starting date corresponds to the first quarter of availability of most of our expectations series). ${ }^{6}$ The data frequency is quarterly.

We use eight realized variables as observables: real output growth, real consumption growth, real investment growth, real government spending growth, real wage growth, log hours, and a short-term nominal interest rate. Data Appendix A provides more details on the series and data transformations that we have used. The real-time series are obtained from the Real Time Data Set for Macroeconomists, made available by the Federal Reserve Bank of Philadelphia (with the exception of interest rates, since their series is not revised). The set of observables corresponds to the seven variables in Smets and Wouters (2007), but with the addition of the growth rate of government spending as an additional observed realized variable here. Other differences with the data set used in Smets and Wouters (2007) are our use of the three-month Treasury Bill yield as our interest rate in place of the Federal Funds rate (a choice that is motivated by the availability of forecasts' data for the three-month rate, but not for the Federal Funds rate) and our real wage series. Here, we choose to use the only wage series that is available in real-time, which corresponds to total wage and salary disbursements (private industries), rather than Smets and Wouters' definition. To maintain consistency in the estimation, therefore, we favor using all real-time series, rather than a mix of real-time and revised series that would be necessary to keep the same wage series as defined in Smets and Wouters (2007). We compute real wages as total wage and salary disbursements divided by total aggregate hours and the GDP deflator. The observable is then the log first difference of the derived real wage series. Hours are also computed using the real-time aggregate weekly hours index divided by civilian noninstitutional population. Observables for output, consumption, investment,

\footnotetext{
${ }^{6}$ Specifically, for each variable, we use the first data release as our relevant time series. We do not attempt to model, instead, the multiple revision process from the date of first release to the final revised vintage. Incorporating revisions in our estimation is complicated by the already large dimensionality of our state space system.
} 
government spending, are obtained as the log first difference of the corresponding variable in real terms. Inflation is calculated as the log first difference of the implicit GDP price deflator. The interest rate is used in levels, but transformed into quarterly, rather than yearly, rates, to match the definition in the model.

In addition to the eight realized variables, at least in the main estimation of interest in the paper, we exploit all available relevant data on expectations: we include expectations about future output growth, future consumption growth, future investment growth, future government spending growth, future inflation, and future interest rates, for horizons ranging from one quarter ahead to five quarters ahead. Therefore, we exploit a total of thirty expectation series. All expectations series are obtained from the Survey of Professional Forecasters, published by the Federal Reserve Bank of Philadelphia. Our series correspond to the mean across forecasters (again, Appendix A provides details on the series). ${ }^{7}$ Data on forecasts for hours and wages are not available and, hence, not included in the estimation. In principle, forecasts regarding employment growth would be available, but their availability starts only from 2003, and, therefore, we omit them.

Figure 1 shows the realized and expectation series that are used in the estimation. To avoid clutter in the figure, we only plot expectations at the one-quarter and four-quarter-ahead horizons for each variable, rather than the full set of expectations. A stylized fact about expectations is that they are generally smoother than the forecasted series; as expected, longer-horizon expectations are considerably smoother than one-quarter-ahead expectations.

3.2. State-Space System. The state space expands considerably with the inclusion of news. For each news shock up to horizon $H$, the state space expands its size by $\sum_{h=1}^{H} h$ : in our case, news at horizons 1 to 5 about each structural disturbance adds 15 rows to the state-space system, for a total of 105 new rows (with coefficient matrices composed by ones and zeros only). The log-linearized equations, along with the laws of motion for the disturbances and news can be written as

$$
\Gamma_{0} \xi_{t}=\Gamma_{1} \xi_{t-1}+\Psi \omega_{t}+\Pi \zeta_{t}
$$

where $\xi_{t}$ collects the fourteen endogenous variables in the model, a subset of the corresponding variables in the associated flexible price economy (necessary to compute the potential output term that enters the Taylor rule), the seven structural disturbances, the expectation terms, and all the news components, $\omega_{t}$ collects the i.i.d. innovations, and $\zeta_{t}$ is a vector of expectational errors, $\eta_{t}=\xi_{t}-E_{t-1} \xi_{t}$, such that $E_{t-1} \eta_{t}=0$. The model can be solved, under the assumption of rational

\footnotetext{
${ }^{7}$ Mansky (2010) emphasized how the use of the mean across forecasters may create a composition bias, caused by the entry and exit of different forecasters over the sample. While we are sympathetic to the use of individual forecasters' data, rather than summary statistics, we abstract from this issue here. We believe that the level of aggregation we impose here is consistent with typical practice in empirical macroeconomics.
} 
expectations and following the approach laid out in Sims (2000), to obtain

$$
\xi_{t}=F \xi_{t-1}+G \omega_{t}
$$

which gives the system transition equation.

The link between observable variables and the theoretical variables in the model is captured by the following set of observation equations:

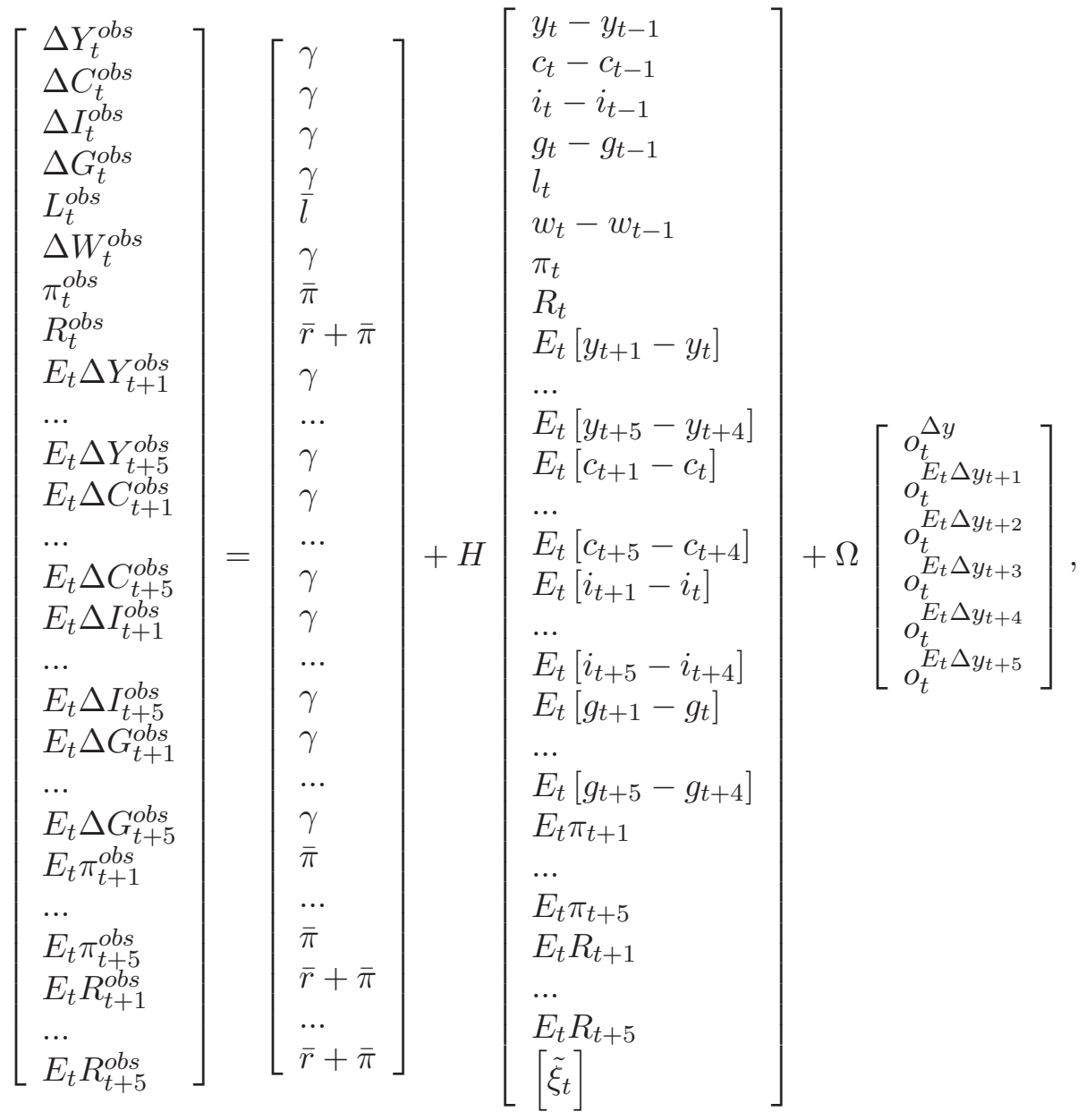

which we can write more compactly as

$$
O B S_{t}=\bar{H}+H \xi_{t}+\Omega o_{t} .
$$

The matrices $H$ and $\Omega$ are selection matrices, composed of ones and zeros: $H$ selects the observable variables within the state vector $\xi_{t}$ (where $\left[\tilde{\xi}_{t}\right]$ contains those state variables in the vector $\xi_{t}$ for which no observables are available), while $\Omega$ selects the measurement errors to enter the observation equations for realized real GDP growth and for the five real GDP growth expectations series. We allow for measurement error terms in the output equations to account for possible differences in the definition of output growth in the model and in the data (also necessary since exports and imports are not explicitly modeled) and to break the tight link implied by the resource constraint equation (2.1). Given that we use observables for output, consumption, investment, and government 
spending, a failure to allow for measurement errors would spuriously assign to the cost of varying capital utilization, $u_{t}$, any difference between these theoretical variables and their relationship in the data; this would also cause bias in the other estimated relations in the model. There are no measurement errors for all the other relations. ${ }^{8}$ The vector $\bar{H}$ contains, instead, steady-state values: $\gamma$ will be estimated, while we will fix $\bar{l}, \bar{\pi}$, and $\bar{r}$, to their sample averages.

The treatment of trends follows Smets and Wouters (2007): we impose a common trend $\gamma$ in output, consumption, investment, government spending, and the real wage. ${ }^{9}$ For now, we assume that agents, when forming expectations, recognize the correct values of the economy's balanced growth rate, $\gamma$, the steady state values of inflation, labor hours, real interest rates, and so forth. Such assumption seems consistent with the overall assumption of rational expectations.

The main novelty in this paper is the use of extensive information from the term structure of survey expectations. We exploit information on one-period-ahead to five-period-ahead output, consumption, investment, and government spending growth, inflation, and interest rate. As made clear by (3.3), observed expectations are, therefore, assumed equal to the rational expectation for the corresponding variable from the model plus a measurement error term in the case of real GDP growth expectations.

To summarize, in the estimation scenario without expectations data, we shall consider seven structural shocks that mirror those in Smets and Wouters (2007), one measurement error to account for differences between our data on real GDP growth and the model definition, and news shocks at horizons one to five for each of the seven structural shocks. In the main estimation of interest, with expectations treated as observables, we add measurement errors for real GDP growth forecasts, for the reason outlined above. The increase in observables is not associated to an equivalent increase in the number of shocks: the existence of several news shocks guarantees that the model is not affected by stochastic singularity (even without the use of measurement errors).

News shocks are now identified from restrictions imposed by changes in expectations at different horizons. In particular, the identification of news is made possible through differences between one, two, and more, period ahead expectations, all formed at the same time $t$, but also from revisions in forecasts formed in $t+1$ about the variable in $t+2$ compared with the previous period $t$ forecast about the variable in $t+2$, and so forth.

We remark that while the state space dimension expands considerably, we exploit a large number of new observable variables without adding a large number of parameters (only the standard

\footnotetext{
${ }^{8}$ Our strategy here differs from the one used in Hirose et al. (2012): we do not add measurement errors to each observed expectations series. the addition of news shocks already guarantees that the system does not suffer from stochastic singularity.

${ }^{9}$ Regarding government spending, we have performed the estimation, either imposing the same trend, or allowing its trend to differ, in order to account for the declining share of government expenditures in GDP. The results are not affected.
} 
deviations for the GDP growth measurement errors). Therefore, even if the estimation is computationally more burdensome, the identification is facilitated by the use of additional thirty-eight observable series.

3.3. Priors. The prior distributions for the structural parameters mirror in most cases those in Smets and Wouters (2007), with some modest differences, and are shown in Table $1 .{ }^{10}$

We revise downward the prior for the habit formation coefficient, which has a mean of 0.5 , rather than 0.7 as in Smets and Wouters (2007). We select priors for the Calvo price and wage stickiness coefficients to match the micro evidence on price rigidity: the prior means equal 0.66, implying prices and wages on average fixed for 9 months (a duration that is consistent with the findings in Nakamura and Steinsson, 2010), with a standard deviation of 0.06. The prior in Smets and Wouters (2007) implied less rigid prices (mean 0.5).

We choose a Gamma prior with mean equal to 1.5 and standard deviation 0.375 for $\sigma_{c}$, the inverse of the intertemporal elasticity of substitution coefficient. Schmitt-Grohé and Uribe (2012) fix, instead, the coefficient to equal 1 in their estimation. Given the importance of the coefficient for business cycle analysis, we estimate this coefficient as well. The elasticity of labor supply is captured by the parameter $\sigma_{l}$ : we assume a Gamma prior with mean equal to 2 and standard deviation 0.4 .

The prior selections that are most relevant here, however, concern the standard deviations of unanticipated and news shocks. We follow Schmitt-Grohé and Uribe (2012) in assuming that the standard deviations follow Gamma priors. Gamma priors with equal values for the mean and standard deviations ensure that values close to 0 are assigned higher probability than positive and larger values and that 0 is also a value with positive probability mass. Given that the model has more shocks than observables, this choice ensures that the data pick the most influential shocks, rather than spuriously forcing each shock to have a positive standard deviation. ${ }^{11}$ As in SchmittGrohé and Uribe (2012), the unanticipated shocks are assumed to account for $75 \%$ of the a priori variance, while the five news shocks for each disturbance account for the remaining $25 \%$; therefore, for each disturbance $j$, we select the prior mean so that $\frac{\sigma_{j}^{2}}{\sigma_{j}^{2}+\sum_{h=1}^{5} \sigma_{\eta_{j, h}}^{2}}=0.75$. The priors, therefore, make sure that news shocks are not unduly favored.

\footnotetext{
${ }^{10}$ Some of the coefficients are fixed to the same values chosen by Smets and Wouters (2007): these are the quarterly depreciation rate $\delta=0.025$, the steady-state price and wage markup parameters $\phi_{p}=\phi_{w}=1.5$, and the Kimball curvature parameters $\epsilon_{p}=\epsilon_{w}=10$; we fix the share of government spending in GDP $g_{y}$ to equal 0.21 , our sample mean, rather than 0.18 . We also fix the discount factor $\beta=0.99$ and the share of capital in production $\alpha=0.3 ; \bar{l}, \bar{\pi}$, and $\bar{r}$ are equal to the variables' sample means.

${ }^{11}$ We have also experimented with possibly less informative Uniform distributions and Inverse Gamma distributions of the type $I G(\epsilon, \epsilon)$, with $\epsilon$ a small positive number, for standard deviations in the estimation. Gelman (2006) discusses how uniform distributions may be unexpectedly informative, with miscalibration toward positive values, when the standard deviations are close to zero, and how results under the previous inverse gamma prior are usually very sensitive to the choice of $\epsilon$. Therefore, we choose here a prior that seeks to impart parsimony by assigning higher probability to standard deviation values near zero (thus potentially shutting down some shocks).
} 
Finally, measurement error terms, when present, are assumed to be i.i.d. We assume that the standard deviation coefficients follow Inverse Gamma prior distributions with mean equal to 0.25 and standard deviations equal to 1 . In our empirical analysis, the measurement error standard deviations appear very well identified and prior choices do not affect in any way the corresponding posterior estimates. In the robustness section, we also repeat some of the estimations by fixing the measurement errors to levels that force them to explain less than $10 \%$ of realized or forecasted output growth variances.

3.4. Estimation Strategy. Before turning to the analysis of the main model with expectations data and news, we would like to understand the contribution of each of our auxiliary choices to the final results. To this scope, we perform a sequence of intermediate estimations before focusing on our baseline model.

First, we re-estimate the model in Smets and Wouters using their original data set, but with 1981:III as the starting date, to be consistent with our subsequent estimations. Their sample ends in 2004:IV. We then extend the Smets and Wouters' model to include news and re-estimate the model on their original, although post-1981, data set.

In our main estimation, however, we will use real-time, rather than revised, data. Therefore, to single out the effect of real-time data, we also re-estimate the Smets and Wouters model with and without news, on our real-time data set, with the updated 1981:III-2011:II sample. Besides the real-time nature of the data used in this estimation, the most important difference is the addition of government spending to the set of observables, which limits the flexibility of the government spending shock to shift around to mask misspecification in the model and to fit other real variables.

Finally, we turn to our main estimation of interest: the estimation of a DSGE model with news shocks and using data on a large set of observed expectations. This case is similar to the previous estimation with real-time data, but with the addition of survey expectations as observables that the estimation under rational expectations will be forced to match.

In the latter case, the model is expressed as in (3.2) and (3.4); the previous four intermediate cases are simplified versions of the same state-space system. For most estimations, we generate one million draws using the Metropolis-Hastings algorithm. For the baseline case, given the expanded size and complexity, we use a longer chain to make sure that we have not settled on a local mode. We report posterior estimates based on the last 500,000 draws. We have repeated the estimation starting from different initial conditions and compared the similarity of posterior estimates. To check convergence, we use trace plots and we check recursive means of the draws. Most posterior distributions have a unique mode, but in few cases, the parameters' posterior distributions appear 
bimodal: we will highlight bimodality issues when they exist in our discussion of results in the following section.

\section{Empirical Results}

4.1. Posterior Estimates. Table 1 shows the estimation results. Columns (1) and (2) display the posterior estimates for the Smets and Wouters' data set, restricted to the post-1981 period, without news and with news shocks. Column (3) refers to the case in which we repeat the estimation with the use of real-time, first-vintage, data series, and with the inclusion of government spending as an observable variable. Column (4) shows the estimation result on the same real-time data set as case (3), but now allowing for news shocks. Finally, column (5) refers to the baseline estimation in the paper. The same specification estimated in column (4) is now required to match a large set of survey expectations that are added to the list of observables. The information contained in expectations is exploited to improve the extraction of the news component over the business cycle. The main comparison of interest in the paper is between cases (2), (4) and (5): the first corresponds to the most common practice of extracting news from revised data and with no information from available expectations, the second adds a better approximation of real-time private-sector knowledge to the estimation, while the third improves over the first two cases, by extrapolating news from expectations data, exploiting how expectations vary across horizons in the same quarter, how expectations at the same horizon are revised from one quarter to the next, and how they interact with realized macroeconomic observations.

For the estimation on the revised Smets and Wouters' sample shown under column (1), most of the results are consistent with Smets and Wouters' (2007) estimates. One issue to point out in this estimation is that there is a clear bimodality in the coefficients reflecting the serial correlation of the risk premium shock and the degree of habit formation in consumption: one mode is characterized by high serial correlation in the exogenous risk premium shock and relatively low habit formation, while the other is characterized by low serial correlation and high habit formation. The mode with high habits - low serial correlation, however, achieves a substantially higher posterior probability (which, however, does not prevent the Markov chain from often visiting the second mode as well). Smets and Wouters' choice of prior mean equal to 0.7 for the habit coefficient would work to reduce the importance of the second mode, while our prior lets the data more freedom to explore and pick any of the two modes. ${ }^{12}$

The estimates also show a significant autocorrelation for technology, government spending, and investment-specific disturbances, while the price and wage markup, and the monetary policy shock

\footnotetext{
${ }^{12}$ We have also estimated the model using the same prior mean as Smets and Wouters: in that case, the posterior mean estimate for habit formation is higher, while the estimate for the risk-premium AR coefficient falls around 0.20 .
} 
are more modestly correlated. The data favor significant degrees of adjustment costs in capital formation $(\varphi=6.12)$, significant rigidity in wages and prices $\left(\xi_{p}=0.76\right.$ and $\left.\xi_{w}=0.86\right)$, high indexation of wages to past inflation $\left(\iota_{w}=0.47\right)$, and more modest inflation indexation in prices $\left(\iota_{p}=0.20\right)$.

Column (3) shows how the results change when the data set is based on real-time vintages, rather than the most recent revised data vintage. There are some differences in the estimates: more importantly, the evidence now favors much larger serial correlation of the risk-premium shock. There are also some differences in the standard deviations of the shocks. The posterior estimates indicate a larger standard deviation for the neutral technology shock and for the wage markup shock, and a lower standard deviation for the government spending shock, since it is now restricted to fit a corresponding observable series, and for the risk-premium shock. The Calvo coefficients are higher $\left(\xi_{p}=0.92\right.$ and $\left.\xi_{w}=0.89\right)$.

The i.i.d. measurement error has a posterior standard deviation equal to 0.55. We have found this estimate to be extremely robust to all specification and estimation choices.

Column (2) reports the posterior estimates for the Smets and Wouters' model with news shocks about each of the seven structural disturbances. In the specification with news, the bimodality between habits and the risk-premium correlation largely disappears, as the data unequivocally pick the mode with high serial correlation of the risk premium shock $\left(\rho_{b}=0.93\right)$. The posterior estimates for the standard deviation of news coefficients fail to provide extensive support in favor of the importance of news. The posterior mean estimates for all except few of the standard deviations fall to values below the respective prior means. All the $95 \%$ credible sets contain the value of 0 . There is not definitive evidence, therefore, that news plays a significant role over the business cycle. An exception may be represented by news about the risk-premium shock: although the priors are updated toward zero, the values of news standard deviations are equal or above the standard deviation of the corresponding unanticipated shock.

The results are similar, but overall more favorable toward news, at least regarding news about future technology and wage markup shocks, when the estimation is performed using real-time data (column (4)). In all cases except monetary policy news at horizons two and five, the credible sets contain values of zero for the standard deviations. Again, most priors for the news coefficients are updated toward zero. Judging the magnitudes of the standard deviations for anticipated and unanticipated shocks, it seems that the news that matters the most refers to the risk-premium shock and to monetary policy.

We compare the fit of models with and without news. The log marginal likelihoods appear to favor in all cases the model specifications with news shocks. Given the different data sets and 
observables used in the estimations, we can compare the fit of the model in column (1) versus (2) with each other, and column (3) versus column (4) with each other. In both cases, the models achieve highest marginal likelihoods when news is included.

Finally, column (5) focuses on the estimates for the baseline case, with real-time data, news shocks, and expectations series as observables. There are significant differences in some of the posterior estimates and even more substantial differences regarding news shocks. Now the majority of credible sets for the news volatilities fall well above zero. The credible sets assign large probabilities to values that indicate a larger importance for news shocks and that fall above the corresponding prior means. In terms of fit, although the estimates are not shown in the table, the model with news in column (5) dominates by several orders of magnitude the alternative model with observed expectations data, but no news (estimated by adding a measurement error for each observed expectation, with inverse gamma prior with mean 0.25 and unitary standard deviation).

We illustrate in more detail the main effects on the estimation obtained by exploiting observed expectations in the next sections.

4.2. Macroeconomic Persistence. The addition of news and the use of subjective expectations from surveys influence the ability of the model to match the persistence of macroeconomic variables. The specifications with news (both with the Smets and Wouters' and our real-time data set) are characterized by posterior estimates revealing lower degrees of habit formation (shifting from $h=0.56$ to $h=0.31$ in the SW data set, and from $h=0.60$ to $h=0.44$ in the real-time data set) and lower capital adjustment costs (from $\varphi=6.12$ to $\varphi=4.32$ in the SW data set, and from $\varphi=5.54$ to $\varphi=3.97$ in the real-time data set). The results, therefore, indicate that news induces additional persistence in the system, which works to reduce the role of some popular endogenous sources of inertia in the model.

But the impact on persistence is much more pronounced in the case with observed expectations and news. The posterior mean for the adjustment cost coefficient falls to 2.22 and for the habit formation coefficient falls to 0.23. The persistence is, however, captured in large part by the exogenous shocks, which have high serial correlation; in particular, the persistence of the riskpremium and the investment-specific disturbances rises close to one. On the other hand, the price markup and monetary policy disturbances are close to i.i.d.

Figure 2 overlaps the posterior distributions for some of the coefficients reflecting the degree of real and nominal frictions required to induce persistence in the model, obtained across three comparable estimation scenarios with the real-time data set ((3) to (5) in Table 1): these are the strength of investment adjustment costs $(\varphi)$, habit formation in consumption $(h)$, stickiness in 
prices and wages $\left(\xi_{p}\right.$ and $\left.\xi_{w}\right)$, and indexation to past inflation in the prices and wages that cannot be re-optimized in any given period $\left(\iota_{p}\right.$ and $\left.\iota_{w}\right)$.

In the model with observed expectations, the posterior distributions all shift to the left: the model is characterized by significantly lower adjustment costs and habit formation, as indicated above, but also by lower rigidity in price and wage contracts $\left(\xi_{p}\right.$ and $\xi_{w}$ now have posterior means equal to 0.85 and 0.70$)$, lower price indexation $\left(\iota_{p}=0.03\right)$, and marginally lower wage indexation $\left(\iota_{w}=0.31\right)$.

4.3. Identification of News. As we hinted before, the baseline estimation in column (5) leads to some important differences regarding the inference of news shocks.

First and more importantly, the identification of news is considerably improved by the use of the available data on expectations. Figure 3 shows the overlapping prior and posterior distributions for each news shock standard deviation coefficient, obtained in the estimation on the Smets and Wouters' data set. Figure 4 presents the same information corresponding to the estimation with real-time data, but without adding survey expectations.

Both figures show that the identification of news, while theoretically possible, is tenuous at best. In many cases, the posterior distributions for the news coefficients largely overlap the prior distributions; in several other cases, they do not overlap, but they still fall very close (the situation is only slightly better in the real-time data set estimation). Overall, we can conclude that data on realized macroeconomic variables contain only limited information that can sharpen the extraction of news shocks. The main differences, when they exist, between priors and posteriors, is that posterior distributions assign larger probabilities to values close to zero and almost no probability to larger values; in other regions, priors are not updated. ${ }^{13}$

The troublesome identification may help explain the variety of results in the literature. DSGE studies range from those showing that news shocks are the main determinant of business cycle fluctuations to those finding that they are utterly unimportant.

Information from observed expectations, at different horizons, can therefore help econometricians to disentangle unanticipated shocks and news over the business cycle.

In Figure 5, we overlap the posterior distributions, along with the common prior distributions, for all news standard deviation coefficients obtained in the model with and without observed expectations (corresponding to cases (5) and (4) in Table 1). It is apparent that, while priors and posteriors are close for the estimation with realized data only, the posterior distributions for news coefficients obtained in the estimation that exploits survey expectations typically fall far from the

\footnotetext{
${ }^{13}$ Problems with identification were apparent in our exercise in other ways: when we estimated the models without expectations' data under different priors for the standard deviations, the posterior distributions correspondingly shifted to reflect the alternative prior choices.
} 
priors. Another indication that the data are now informative is that the posterior distributions are much narrower around their mean than in the previous cases. ${ }^{14}$ The posterior means often fall above the corresponding prior means. In some cases, the data favor values of the news' volatilities that are in the right tail of the prior distribution (e.g., $\eta_{\phi, 1}$ ): we take this as suggestive evidence that the importance of news would be even stronger if we didn't embrace the strategy of weighing against news in our prior selections.

The use of survey expectations leads to extracted news series that substantially differ from those obtained in estimations with realized variables only. Figure 6 shows the scatter plots of the estimated news (posterior mean across draws), for each disturbance and summing over the different horizons, across estimations with and without expectations as observables. ${ }^{15}$ The inferred news series substantially differ: their correlations across the two estimations are typically close to zero, and range from -0.38 for the investment-specific technology news to 0.46 for monetary policy news.

4.4. Shocks and Fluctuations. The main question that the macroeconomic literature on news has been pondering focuses on whether exogenous shifts in news are responsible for a large portion of aggregate fluctuations. Tables 2 to 6 report our results on the forecast error variance decomposition for the set of realized macroeconomic variables that we have used. ${ }^{16}$

When news shocks are not present, and the data set corresponds to the revised Smets and Wouters' observables, the main drivers of fluctuations are represented by the investment-specific $(38.67 \%)$, government spending $(25.52 \%)$, and to a lesser extent, monetary policy $(18.47 \%)$, shocks (Table 2). The addition of government spending data in the estimation reduces the role of the government spending shock: the investment-specific, risk-premium, and monetary policy, shocks rise in importance to account for its share of fluctuations (Table 3).

Turning to the models with news, in the Smets and Wouters' data set, the estimation does not single out news as a key driver of fluctuations. News shocks combine to account for $20 \%$ of the forecast error variance in output growth. Moreover, the majority of the effects from news are attributed to news about a future demand disturbance, namely shocks about the risk-premium, and to news about monetary policy, rather than news about technology, which has been typically emphasized in the "news view" literature. These results are, therefore, consistent with the findings in Khan and Tsoukalas (2012). In the real-time data set, news accounts for a much larger role:

\footnotetext{
${ }^{14}$ Some exceptions for which identification remains weak are news about the risk-premium and wage markups at short horizons.

${ }^{15}$ If the estimated news shocks remain identical in the two cases, the observations should all fall on the 45 degree line in the scatter plots.

${ }^{16}$ The forecast error variance decomposition results are obtained for each estimated model with coefficients fixed at the posterior mode.
} 
news about future monetary policy, of the kind emphasized in Milani and Treadwell (2012) play a particularly important role. Again, news about demand plays a larger role than news about neutral and investment-specific technology shocks.

As discussed in the estimation section, we are, however, unwilling to assign a lot of confidence to the results, since the majority of news shocks suffered from problematic identification. The identification was, however, largely improved in our baseline scenario, in which we exploited direct expectations data.

In this case, as shown in Table 6, we find that news explains a large portion of business cycle fluctuations. While the single most important disturbance is the investment-specific shock, which accounts for almost $40 \%$ of real output growth variance, news shocks also play a significant role, adding up to explain another $40 \%$. News also accounts for between one third and close to one half of the fluctuations in other variables as consumption and investment growth, labor hours, real wage growth, inflation, and interest rates, as well. Anticipations account for $16 \%$ of government spending changes. The most important source of news is related to investment-specific technology shocks, and it is at a short-run horizon: this explains $10 \%$ of output variation. News at longer horizons regarding future risk-premium and wage markup shocks, and at shorter horizons regarding monetary policy, also account for nontrivial shares. News about cost-push price markup shocks mostly matter for inflation.

\section{Robustness}

In the baseline estimation with observed expectations and news shocks, we have used the realtime vintage of each observable. While this is our preferred choice, we here assess the sensitivity of our main conclusions to the use of revised current-vintage, rather than real-time, data. Hence, we re-estimate the model specification corresponding to column 5 (in Table 1), now using the same Smets and Wouters data set, but augmented to include expectations data. The observed expectation series are unchanged. We report the share of output growth variance that can be attributed to news in Table 7. News now accounts for $50 \%$ of the forecast error variance in real GDP growth.

Our estimations so far have followed Smets and Wouters (2007) in assuming that real variables grow at a constant common rate along the economy's balanced growth path. This assumption, although theoretically more rigorous, may be severely at odds with the data. We investigate the impact of relaxing the common trend assumption in the estimation of the baseline model. The model is re-estimated now assuming a linear trend for each real variable in the spirit of Smets and Wouters (2003), instead. The new assumption loses some theoretical appeal, but it can be seen as a more purely statistical alternative to the benchmark case. Table 7 shows that news shocks now 
explain $45 \%$ of fluctuations. The data do not support the balanced growth path restriction: the log marginal likelihood is considerably higher when variable-specific linear trends are used (757.5 rather than 715.94$)$.

We also recognize that news shocks are inserted and analyzed in very different environments in the literature, which may be partially responsible for the different findings. We have chosen to work with a sticky-wage sticky-price model. Schmitt-Grohé and Uribe (2012) uncover a major role of news in a model with flexible prices, instead. As an additional robustness check, therefore, we re-estimate the baseline model (reverting to the original real-time data, balanced growth path, specification), but now shutting down some of the nominal and real rigidities in the model: we fix the Calvo price and wage stickiness coefficients to 0.01, and the price and wage indexation coefficients to 0 . News accounts for $29 \%$ of the share of the output growth variance. Interestingly, news are found more important in the specification with sticky prices than in the one with flexible prices. The flexible-price model, however, fits the data extremely poorly.

Finally, we investigate the sensitivity of the results to restricting the measurement error variances to fall below $10 \%$ of the variance of the respective realized or expected variable. The main results are similar, with news now explaining $44 \%$ of fluctuations.

\section{Conclusions}

A growing literature focuses on the extraction of anticipations or 'news' about future macroeconomic shocks and studies their contribution to business cycle fluctuations. This paper has exploited a large range of observed expectation series, at different horizons, and for several variables, to sharpen the identification of business cycle news. Since estimated DSGE models under rational expectations typically disentangle news from unanticipated innovations through the effect that news shocks have on expectations, it seems natural to use the information contained in expectations to extract the news component.

The results show that the use of expectations data is indeed crucial. When the model is estimated using realized variables only, almost all news coefficients are very weakly or non-identified. The limited information in the data seems to point in the direction of revising the priors for news components toward zero. When data on observed expectations are exploited in the estimation of the DSGE model with anticipated and unanticipated shocks, the coefficients related to news are typically well identified. The posterior estimates for the standard deviations of news often fall above the respective prior means, and values of zero fall outside the corresponding $95 \%$ credible sets. News shocks play a sizable role over the business cycle: the ensemble of news accounts for roughly $40 \%$ of fluctuations. 


\section{REFERENCES}

[1] Avdjiev, S., 2011. "News Driven Business Cycles and Data on Asset Prices in Estimated DSGE Models," BIS Working Paper No. 358.

[2] Barattieri, A., Basu, S., and P. Gottschalk, 2010. "Some Evidence on the Importance of Sticky Wages", NBER Working Paper No. 16130.

[3] Beaudry, P., and B. Lucke, 2009. "Letting Different Views about Business Cycles Compete, NBER Macroeconomics Annual, 41356.

[4] Beaudry, P., and F. Portier, 2006. "Stock Prices, News, and Economic Fluctuations," American Economic Review, vol. 96(4), pages 1293-1307.

[5] Benhabib, J. and R.E.A. Farmer, 1999. 'Indeterminacy and Sunspots in Macroeconomics', in (J.B. Taylor and M. Woodford, eds.), Handbook of Macroeconomics, vol. 1, part 1, pp. 387-448, Amsterdam: Elsevier.

[6] Christiano, L.J., Eichenbaum, M., and C.L. Evans, 2005. "Nominal Rigidities and the Dynamic Effects of a Shock to Monetary Policy," Journal of Political Economy 113, 1-45.

[7] Del Negro, M. and S. Eusepi, 2011. "Fitting Observed Inflation Expectations", Journal of Economic Dynamics and Control, 35(12), 2105-2131.

[8] Forni, M., Gambetti, L., and L. Sala, 2011. "No News in Business Cycles," CEPR Discussion Papers 8274.

[9] Fujiwara, I., Hirose, Y., and M. Shintani, 2011. "Can News Be a Major Source of Aggregate Fluctuations? A Bayesian DSGE Approach", Journal of Money, Credit and Banking 43(1), 129.

[10] Gelman, A., 2006. "Prior Distributions for Variance Parameters in Hierarchical Models", Bayesian Analysis, $1(3), 515-533$.

[11] Haberler, G., 1937. Prosperity and Depression: A theoretical analysis of cyclical movements, Geneva: League of Nations.

[12] Hirose, Y., and T. Kurozumi, 2012. "Identifying News Shocks with Forecast Data," CAMA Working Papers 2012-01, Australian National University, Centre for Applied Macroeconomic Analysis.

[13] Jaimovich, N., and S. Rebelo, 2009. "Can News about the Future Drive the Business Cycle?," American Economic Review, vol. 99(4), 1097-1118.

[14] Justiniano, A., Primiceri, G.E., and A. Tambalotti, 2010. "Investment Shocks and Business Cycles," Journal of Monetary Economics, vol. 57(2), pages 132-145.

[15] Keynes, J.M., 1936. The General Theory of Employment, Interest and Money. London: MacMillan and Co.

[16] Khan, H.U., and J. Tsoukalas, 2012. "The Quantitative Importance of News Shocks in Estimated DSGE Models", Journal of Money, Credit and Banking, 44(8), 15351561.

[17] Leeper, E.M., Walker, T.B., and S.C. Yang, 2008. "Fiscal Foresight: Analytics and Econometrics", NBER WP 14028 .

[18] Lorenzoni, G., 2011. "News and Aggregate Demand Shocks," Annual Review of Economics, 3, 537-557.

[19] Mansky, C.F., 2011. "Interpreting and Combining Heterogeneous Survey Forecasts", in M. Clements and D. Hendry (editors), Oxford Handbook on Economic Forecasting, Chapter 16, 457-472, Oxford: Oxford University Press.

[20] Mertens, K., and M.O. Ravn, 2010. "Measuring the Impact of Fiscal Policy in the Face of Anticipation: A Structural VAR Approach", Economic Journal, 120(544), 393-413.

[21] Milani, F., 2011. "Expectation Shocks and Learning as Drivers of the Business Cycle", Economic Journal, 121(552), 379-401.

[22] Milani, F., 2012a. "The Modeling of Expectations in Empirical DSGE Models: a Survey", Advances in Econometrics, 28, 3-38.

[23] Milani, F., 2012b. "Sentiment and the U.S. Business Cycle", mimeo, UC Irvine.

[24] Milani, F., and A. Rajbhandari, 2012. "Expectation Formation and Monetary DSGE Models: Beyond the Rational Expectations Hypothesis", Advances in Econometrics, 28, 253-288.

[25] Milani, F., and J. Treadwell, 2012. "The Effects of Monetary Policy "News" and "Surprises"”, forthcoming, Journal of Money, Credit and Banking, 44(8), 1667-1692.

[26] Nakamura, E., and J. Steinsson, 2008. "Five Facts about Prices: A Reevaluation of Menu Cost Models," The Quarterly Journal of Economics, 123(4), 1415-1464.

[27] Ormeno, A., 2011. 'Disciplining Expectations: Using Survey Data in Learning Models', Working Paper, Universitat Pompeu Fabra.

[28] Pesaran, M.H., and M. Weale, 2006. "Survey Expectations," Handbook of Economic Forecasting, Amsterdam: Elsevier.

[29] Pigou, A.C., 1927. Industrial Fluctuations, London: MacMillan.

[30] Rajbhandari, A., 2012. "Transmission of News Shocks in an Open Economy DSGE model", mimeo, UC Irvine.

[31] Schmitt-Grohé, S., and M. Uribe, 2012, "What's News in Business Cycles?", Econometrica, 80(6), 27332764.

[32] Sims, C.A., 2000. "Solving Linear Rational Expectations Models", Computational Economics, $20,1-20$.

[33] Smets, F., and R. Wouters, 2003. "An Estimated Dynamic Stochastic General Equilibrium Model of the Euro Area," Journal of the European Economic Association, 1(5), 1123-1175. 
[34] Smets, F., and R. Wouters, 2007. "Shocks and Frictions in US Business Cycles: A Bayesian DSGE Approach," American Economic Review, 97(3), 586-606. 


\section{A. DATA APPENDIX}

Our data are obtained from the Real Time Data Set for Macroeconomists and from Survey of Professional Forecasters (SPF). For each expectations series, the SPF has a link to "real time data available for this variable" leading to real-time observations for the corresponding variable from the real-time data set for macroeconomists. We choose these series as our realized macroeconomic variables in the estimation. When expectation series are not available, we still use the series from the Real Time Data Set for Macroeconomists that match the variables in the model (real wage and hours). Real-time data are not needed for the interest rate series, which is not subject to revisions. Our observed series include:

- $\Delta Y_{t}^{\text {obs }}$ : We use the Real GDP series (acronym ROUTPUT), billions of dollars, seasonally adjusted, from the Real Time Data Set for Macroeconomists, available at the Federal Reserve Bank of Philadelphia. We use the first available vintage for each observation. For the first available vintage of each observation, we compute the log first difference as $\Delta Y_{t}^{\text {obs }}=\log \left(Y_{t}^{\text {obs }} / Y_{t-1}^{\text {obs }}\right)$.

- $\Delta C_{t}^{o b s}$ : We use the Real Personal Consumption Expenditure series (acronym RCON), billions of dollars, seasonally adjusted, from the Real Time Data Set for Macroeconomists, available at the Federal Reserve Bank of Philadelphia. We use the first available vintage for each observation. We compute the $\log$ first difference as $\Delta C_{t}^{\text {obs }}=\log \left(C_{t}^{\text {obs }} / C_{t-1}^{o b s}\right)$.

- $\Delta I_{t}^{o b s}$ : We use the sum of Real Nonresidential fixed investment (acronym RINVBF) and Real Residential Fixed Investment series (acronym RINVRESID), billions of dollars, seasonally adjusted, from the Real Time Data Set for Macroeconomists, available at the Federal Reserve Bank of Philadelphia. We use the first available vintage for each observation. We compute the log first difference as $\Delta I_{t}^{o b s}=\log \left(I_{t}^{o b s} / I_{t-1}^{o b s}\right)$.

- $\Delta G_{t}^{\text {obs }}$ : We use the Real Federal Government Consumption Expenditures \& Gross Investment series (acronym RGF), billions of dollars, seasonally adjusted, from the Real Time Data Set for Macroeconomists, available at the Federal Reserve Bank of Philadelphia. We use the first available vintage for each observation. We compute the $\log$ first difference as $\Delta G_{t}^{o b s}=\log \left(G_{t}^{\text {obs }} / G_{t-1}^{\text {obs }}\right)$.

- $L_{t}^{o b s}$ : We use the Index of Aggregate Weekly Hours: Total (acronym H), index level, seasonally adjusted, from the Real Time Data Set for Macroeconomists, available at the Federal Reserve Bank of Philadelphia. We use the first available vintage for each observation. The index base level varies across observations, therefore, we rescale it to be consistent over the full sample. We use the variable in $\log$ levels $L_{t}^{o b s}=\log L_{t}^{o b s}$.

- $\Delta W_{t}^{\text {obs }}$ : We use the Wage and Salary Disbursements series (acronym WSD), billions of dollars, seasonally adjusted, from the Real Time Data Set for Macroeconomists, available at the Federal Reserve Bank of Philadelphia. We use the first available vintage for each observation. We compute the real wage by dividing by the real-time price index for GDP (described below) and use the log first difference: $\Delta W_{t}^{o b s}=\log \left(W_{t}^{o b s} / W_{t-1}^{o b s}\right)$.

- $\pi_{t}^{\text {obs }}$ : We use the Price Index for Gross Domestic Product (acronym P), index level, seasonally adjusted, from the Real Time Data Set for Macroeconomists, available at the Federal Reserve Bank of Philadelphia. We use the first available vintage for each observation. Inflation is computed as $\pi_{t}^{o b s}=\log \left(P_{t}^{o b s} / P_{t-1}^{o b s}\right)$.

- $R_{t}^{\text {obs: }}$ We use the 3-Month Treasury Bill Rate series (acronym WSD), percentage points, not seasonally adjusted, quarterly average, from the Survey of Professional Forecasters, available at the Federal Reserve Bank of Philadelphia. Since forecasters are asked about their expectation about the interest rate in the previous quarter $\left(E_{t} R_{t-1}\right)$, and the interest rate is definitely known to forecasters a quarter later, we use this as our series for $R_{t}$ (i.e., $R_{t}=E_{t+1} R_{t}$ ). We convert the interest rate into quarterly rates for consistency with the corresponding model variable: $R_{t}^{o b s}=R_{t}^{o b s, 1 Y} / 4$.

To the previous list of observable realized variables, we add the following list of expectations series:

- $E_{t} \Delta Y_{t+j}^{o b s}$, for $j=1,2,3,4,5$ : We use the Forecasts for the Real GDP series (corresponding to columns 4 to 8 in the SPF File, acronyms RGDP2, RGDP3, RGDP4, RGDP5, RGDP6), billions of dollars, seasonally adjusted, from the Survey of Professional Forecasters, available at the Federal Reserve Bank of Philadelphia. We use the mean response across forecasters.

- $E_{t} \Delta C_{t+j}^{o b s}$, for $j=1,2,3,4,5$ : We use the Forecasts for the Real Personal Consumption Expenditures series (acronyms RCONSUM2, RCONSUM3, RCONSUM4, RCONSUM5, RCONSUM6), billions of dollars, seasonally adjusted, from the Survey of Professional Forecasters, available at the Federal Reserve Bank of Philadelphia. We use the mean response across forecasters.

- $E_{t} \Delta I_{t+j}^{o b s}$, for $j=1,2,3,4,5$ : We use the sum for the Forecasts for the Real Nonresidential Fixed Investment and Real Residential Fixed Investment series (acronyms RNRESIN2 to RNRESIN6 and 
RRESINV2 to RRESINV6), billions of dollars, seasonally adjusted, from the Survey of Professional Forecasters, available at the Federal Reserve Bank of Philadelphia. We use the mean response across forecasters.

- $E_{t} \Delta G_{t+j}^{\text {obs }}$, for $j=1,2,3,4,5$ : We use the Forecasts for the Real Federal Government Consumption \& Gross Investment series (acronyms RFEDGOV2 to RFEDGOV6), billions of dollars, seasonally adjusted, from the Survey of Professional Forecasters, available at the Federal Reserve Bank of Philadelphia. We use the mean response across forecasters.

- $E_{t} \pi_{t+j}^{o b s}$, for $j=1,2,3,4,5$ : We use the Forecasts for the Price Index for GDP series (acronyms PGDP2 to PGDP6), index level, seasonally adjusted, from the Survey of Professional Forecasters, available at the Federal Reserve Bank of Philadelphia. We use the mean response across forecasters.

- $E_{t} R_{t+j}^{o b s}$, for $j=1,2,3,4,5$ : We use the Forecasts for the 3-Month Treasury Bill Rate series (acronyms TBILL2 to TBILL6), percentage points, not seasonally adjusted, quarterly average, from the Survey of Professional Forecasters, available at the Federal Reserve Bank of Philadelphia. We use the mean response across forecasters. 


\begin{tabular}{|c|c|c|c|c|c|c|}
\hline & \multirow[t]{3}{*}{ Prior } & \multicolumn{5}{|c|}{ Posterior Estimates } \\
\hline & & SW & $\mathrm{SW}+$ News & $\mathrm{RT}$ & RT + News & $\begin{array}{c}\text { BASELINE } \\
(\mathrm{RT}+\mathrm{News}+\mathrm{OE})\end{array}$ \\
\hline & & (1) & $(2)$ & $(3)$ & $(4)$ & $(5)$ \\
\hline$\varphi$ & $\mathrm{G}[4,1.5]$ & $6.12[2.88,8.36]$ & $4.32[2.08,6.56]$ & $5.54[3.64,7.44]$ & $3.97[2.02,5.44]$ & $2.22[1.78,2.63]$ \\
\hline$h$ & $\mathrm{~B}[0.5,0.15]$ & $0.56[0.35,0.73]$ & $0.31[0.17,0.43]$ & $0.60[0.50,0.71]$ & $0.44[0.30,0.57]$ & $0.23[0.19,0.27]$ \\
\hline$\sigma_{c}$ & $\mathrm{G}[1.5,0.375]$ & $1.81[1.40,2.25]$ & $1.46[0.99,1.95]$ & $1.46[1.03,1.88]$ & $1.45[0.99,1.88]$ & $2.70[2.53,2.89]$ \\
\hline$\sigma_{l}$ & $\mathrm{G}[2,0.4]$ & $1.82[1.21,2.38]$ & $1.63[1.12,2.14]$ & $1.59[1.04,2.12]$ & $1.81[1.24,2.40]$ & $1.25[0.78,1.70]$ \\
\hline$\xi_{p}$ & $\mathrm{~B}[0.66,0.06]$ & $0.76[0.72,0.81]$ & $0.79[0.75,0.83]$ & $0.92[0.90,0.94]$ & $0.91[0.88,0.93]$ & $0.85[0.83,0.87]$ \\
\hline$\xi_{w}$ & $\mathrm{~B}[0.66,0.06]$ & $0.86[0.81,0.91]$ & $0.83[0.78,0.87]$ & $0.89[0.85,0.94]$ & $0.86[0.82,0.90]$ & $0.70[0.61,0.79]$ \\
\hline$\iota_{p}$ & $\mathrm{~B}[0.5,0.15]$ & $0.20[0.07,0.33]$ & $0.15[0.06,0.24]$ & $0.21[0.08,0.34]$ & $0.15[0.06,0.24]$ & $0.03[0.01,0.05]$ \\
\hline$\iota_{w}$ & $\mathrm{~B}[0.5,0.15]$ & $0.47[0.25,0.69]$ & $0.42[0.19,0.65]$ & $0.42[0.20,0.64]$ & $0.39[0.19,0.61]$ & $0.31[0.12,0.50]$ \\
\hline$\psi$ & $\mathrm{B}[0.5,0.15]$ & $0.64[0.49,0.80]$ & $0.70[0.55,0.85]$ & $0.50[0.31,0.70]$ & $0.24[0.11,0.39]$ & $0.95[0.93,0.96]$ \\
\hline$\Phi$ & $\mathrm{N}(1.5,0.25)$ & $1.98[1.76,2.20]$ & $1.97[1.76,2.20]$ & $1.76[1.55,1.97]$ & $1.68[1.48,1.87]$ & $1.43[1.35,1.51]$ \\
\hline$\rho_{R}$ & $\mathrm{~B}[0.75,0.1]$ & $0.88[0.85,0.92]$ & $0.91[0.88,0.94]$ & $0.95[0.93,0.97]$ & $0.91[0.87,0.95]$ & $0.97[0.97,0.98]$ \\
\hline$r_{\pi}$ & $\mathrm{N}(1.5,0.125)$ & $1.53[1.32,1.73]$ & $1.55[1.38,1.73]$ & $1.51[1.30,1.71]$ & $1.44[1.22,1.67]$ & $1.40[1.21,1.60]$ \\
\hline$r_{y}$ & $\mathrm{~N}(0.125,0.05)$ & $0.19[0.13,0.26]$ & $0.21[0.17,0.26]$ & $0.19[0.12,0.25]$ & $0.24[0.18,0.31]$ & $0.26[0.22,0.30]$ \\
\hline$r_{\Delta y}$ & $\mathrm{~N}(0.125,0.05)$ & $0.18[0.12,0.23]$ & $0.16[0.12,0.20]$ & $0.13[0.09,0.17]$ & $0.04[0.01,0.07]$ & $0.08[0.07,0.09]$ \\
\hline$\gamma$ & $\mathrm{N}(0.5,0.2)^{*}$ & $0.51[0.46,0.56]$ & $0.55[0.50,0.60]$ & $0.57[0.53,0.61]$ & $0.56[0.53,0.60]$ & $0.53[0.50,0.56]$ \\
\hline$\rho_{a}$ & $\mathrm{~B}[0.5,0.2]$ & $0.93[0.90,0.97]$ & $0.92[0.89,0.96]$ & $0.96[0.95,0.98]$ & $0.96[0.94,0.98]$ & $0.96[0.96,0.97]$ \\
\hline$\rho_{b}$ & $\mathrm{~B}[0.5,0.2]$ & $0.46[0.14,0.96]$ & $0.93[0.89,0.97]$ & $0.97[0.95,0.99]$ & $0.97[0.96,0.99]$ & $0.97[0.97,0.98]$ \\
\hline$\rho_{g}$ & $\mathrm{~B}[0.5,0.2]$ & $0.96[0.95,0.98]$ & $0.97[0.95,0.99]$ & $0.98[0.96,0.99]$ & $0.97[0.96,0.99]$ & $0.99[0.99,0.99]$ \\
\hline$\rho_{g a}$ & $\mathrm{~N}(0.5,0.25)$ & $0.61[0.24,0.99]$ & $0.72[0.33,1.10]$ & $0.48[0.22,0.73]$ & $0.45[0.19,0.70]$ & $0.30[0.19,0.41]$ \\
\hline$\rho_{\phi}$ & $\mathrm{B}[0.5,0.2]$ & $0.83[0.72,0.94]$ & $0.71[0.52,0.93]$ & $0.88[0.80,0.96]$ & $0.62[0.31,0.94]$ & $0.99[0.99,1-\mathrm{e} 3]$ \\
\hline$\rho_{p}$ & $\mathrm{~B}[0.5,0.2]$ & $0.26[0.11,0.41]$ & $0.12[0.02,0.21]$ & $0.23[0.07,0.39]$ & $0.15[0.02,0.26]$ & $0.02[0.00,0.03]$ \\
\hline$\rho_{w}$ & $\mathrm{~B}[0.5,0.2]$ & $0.44[0.23,0.63]$ & $0.21[0.03,0.38]$ & $0.35[0.11,0.60]$ & $0.18[0.03,0.32]$ & $0.67[0.55,0.78]$ \\
\hline$\rho_{m p}$ & $\mathrm{~B}[0.5,0.2]$ & $0.40[0.26,0.53]$ & $0.29[0.13,0.45]$ & $0.46[0.35,0.58]$ & $0.79[0.66,0.91]$ & $0.03[0.00,0.05]$ \\
\hline$\sigma_{a}$ & $\mathrm{G}[0.5,0.5]^{*}$ & $0.34[0.30,0.39]$ & $0.31[0.24,0.36]$ & $0.57[0.51,0.63]$ & $0.50[0.41,0.59]$ & $0.66[0.59,0.74]$ \\
\hline$\sigma_{b}$ & $\mathrm{G}[0.5,0.5]^{*}$ & $0.15[0.05,0.21]$ & $0.02[0.00,0.05]$ & $0.05[0.03,0.06]$ & $0.01[0.00,0.02]$ & $0.03[0.02,0.04]$ \\
\hline$\sigma_{g}$ & $\mathrm{G}[2,2]^{*}$ & $2.32[2.04,2.61]$ & $1.87[1.49,2.23]$ & $1.21[1.07,1.33]$ & $1.09[0.90,1.29]$ & $1.15[1.03,1.27]$ \\
\hline$\sigma_{\phi}$ & $\mathrm{G}[0.75,0.75]^{*}$ & $0.40[0.31,0.47]$ & $0.41[0.30,0.51]$ & $0.45[0.35,0.55]$ & $0.55[0.38,0.70]$ & $1.50[1.29,1.72]$ \\
\hline$\sigma_{p}$ & $\mathrm{G}[0.3,0.3]^{*}$ & $0.13[0.10,0.15]$ & $0.14[0.11,0.16]$ & $0.18[0.14,0.21]$ & $0.17[0.15,0.20]$ & $0.24[0.21,0.27]$ \\
\hline$\sigma_{w}$ & $\mathrm{G}[0.5,0.5]^{*}$ & $0.20[0.15,0.26]$ & $0.22[0.17,0.27]$ & $0.39[0.27,0.50]$ & $0.41[0.34,0.49]$ & $0.43[0.35,0.51]$ \\
\hline$\sigma_{m p}$ & $\mathrm{G}[0.3,0.3]^{*}$ & $0.17[0.15,0.20]$ & $0.10[0.06,0.13]$ & $0.15[0.12,0.17]$ & $0.04[0.00,0.07]$ & $0.15[0.14,0.17]$ \\
\hline$\sigma_{o_{\Delta y}}$ & $\operatorname{IG}[0.25,1]$ & & & $0.55[0.49,0.62]$ & $0.59[0.52,0.65]$ & $0.52[0.46,0.57]$ \\
\hline$\sigma_{O_{E \Delta y_{1}}}$ & $\mathrm{IG}[0.25,1]$ & & & & & $0.26[0.23,0.29]$ \\
\hline$\sigma_{O_{E \Delta y_{2}}}$ & $\mathrm{IG}[0.25,1]$ & & & & & $0.14[0.12,0.15]$ \\
\hline$\sigma_{O_{E \Delta y_{3}}}$ & $\operatorname{IG}[0.25,1]$ & & & & & $0.12[0.10,0.13]$ \\
\hline$\sigma_{O_{E \Delta y_{4}}}$ & $\mathrm{IG}[0.25,1]$ & & & & & $0.10[0.09,0.11]$ \\
\hline$\sigma_{O_{E \Delta y_{5}}}$ & $\mathrm{IG}[0.25,1]$ & & & & & $0.11[0.09,0.12]$ \\
\hline $\operatorname{Marg} L$ & & -487.05 & -484.88 & -1059.64 & -1047.58 & 715.94 \\
\hline
\end{tabular}

Table 1 (part a) - Prior distributions and posterior estimates, for structural, (unanticipated) shock, and measurement error parameters. 


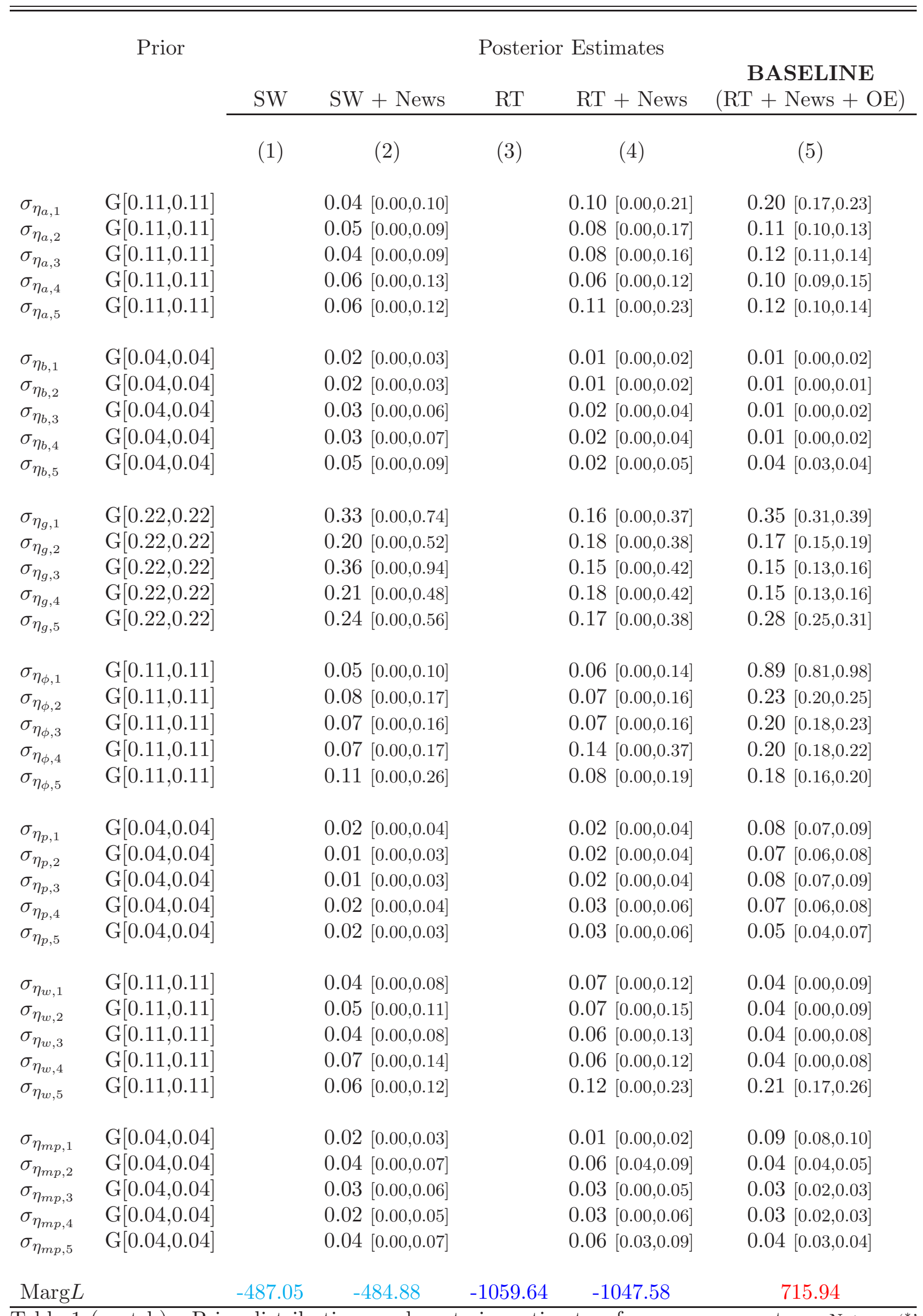

Table 1 (part b) - Prior distributions and posterior estimates, for news parameters. Note: $\mathrm{a}^{\text {(*) }}$ next to the prior denotes differences in priors across some model specifications. For $\gamma$, a $\mathrm{N}(0.5,0.2)$ prior is used for 
estimations with Smets-Wouters data, while a $\mathrm{N}(0.65,0.025)$ prior is used for estimations with real-time data; the tighter prior is chosen to have mean equal to the sample average of the real GDP growth rate, in order to imply a reasonable detrended output series (other assumptions on the trend are investigated in the robustness checks, see Table 7). For the standard deviation coefficients of unanticipated shocks, the priors shown in the table are for the estimated models without news; in the models with news, the priors are chosen so that the variance of each unanticipated shock equals $75 \%$ of the total variance of the corresponding disturbance (e.g., the prior mean for $\sigma_{a}$, the unanticipated technology shock, which is 0.5 in the model without news, becomes 0.433 in the model with news, so that it accounts for $75 \%$ of the total variance, with the five news shocks accounting for the remaining $25 \%$ of the prior variance). Column (1) refers to the estimation with Smets and Wouters' (2007) data set, column (2) to the estimation with the same data set and the addition of news shocks, column (3) refers to the estimation with realtime data, column (4) to the estimation with real-time data and news shocks, and column (5) presents the baseline estimation results, obtained for the real-time data set, the model expanded to include news shocks, and the use of expectation series as observables. 


\begin{tabular}{|c|c|c|c|c|c|c|c|c|}
\hline & & $\Delta Y^{o b s}$ & $\Delta C^{o b s}$ & $\Delta I^{o b s}$ & $H^{o b s}$ & $\Delta W^{o b s}$ & $\pi^{o b s}$ & $R^{o b s}$ \\
\hline Technology & $\varepsilon_{t}^{a}$ & 2.63 & 2.48 & 2.23 & 5.10 & 0.30 & 3.42 & 7.94 \\
\hline Risk-Premium & $\varepsilon_{t}^{b}$ & 13.52 & 45.38 & 1.56 & 1.62 & 0.02 & 0.02 & 43.61 \\
\hline Govt. Spending & $\varepsilon_{t}^{g}$ & 25.52 & 1.25 & 0.43 & 10.14 & 0.02 & 1.73 & 3.46 \\
\hline Investment-Specific Tech. & $\varepsilon_{t}^{\phi}$ & 38.67 & 12.19 & 88.09 & 60.35 & 2.62 & 19.33 & 59.44 \\
\hline Price Markup & $\varepsilon_{t}^{p}$ & 0.50 & 0.55 & 0.23 & 0.32 & 8.14 & 42.92 & 0.57 \\
\hline Wage Markup & $\varepsilon_{t}^{w}$ & 0.70 & 1.13 & 0.23 & 3.16 & 88.06 & 30.02 & 5.83 \\
\hline Monetary Policy & $\varepsilon_{t}^{m p}$ & 18.47 & 37.02 & 7.24 & 19.31 & 0.85 & 2.56 & 19.15 \\
\hline
\end{tabular}

Table 2 - Forecast Error Variance Decomposition. Smets and Wouters Model, 1981:III-2004:IV sample, no news.

\begin{tabular}{lccccccccc}
\hline & & $\Delta Y^{\text {obs }}$ & $\Delta C^{\text {obs }}$ & $\Delta I^{\text {obs }}$ & $\Delta G^{\text {obs }}$ & $H^{\text {obs }}$ & $\Delta W^{\text {obs }}$ & $\pi^{\text {obs }}$ & $R^{\text {obs }}$ \\
\hline Technology & & & & & & & & \\
& $\varepsilon_{t}^{a}$ & 5.56 & 11.08 & 1.66 & 2.45 & 5.96 & 0.23 & 0.71 & 2.31 \\
Risk-Premium & $\varepsilon_{t}^{b}$ & 24.08 & 41.04 & 5.86 & 0.00 & 25.84 & 1.90 & 25.19 & 72.56 \\
Govt. Spending & $\varepsilon_{t}^{g}$ & 4.02 & 0.43 & 0.01 & 97.55 & 1.46 & 0.00 & 0.02 & 0.09 \\
Investment-Specific Tech. & $\varepsilon_{t}^{\phi}$ & 41.67 & 9.53 & 85.07 & 0.00 & 44.57 & 1.14 & 1.82 & 21.29 \\
Price Markup & $\varepsilon_{t}^{p}$ & 0.31 & 0.28 & 0.14 & 0.00 & 0.19 & 6.03 & 89.75 & 0.07 \\
Wage Markup & $\varepsilon_{t}^{w}$ & 0.62 & 0.94 & 0.30 & 0.00 & 1.46 & 89.63 & 2.12 & 0.45 \\
Monetary Policy & $\varepsilon_{t}^{m p}$ & 23.73 & 36.70 & 6.95 & 0.00 & 20.53 & 1.07 & 0.39 & 3.23 \\
\hline
\end{tabular}

Table 3 - Forecast Error Variance Decomposition. Estimation with real-time data and government spending series, 1981:III-2011:I sample, no news. 


\begin{tabular}{|c|c|c|c|c|c|c|c|c|}
\hline & & $\Delta Y^{o b s}$ & $\Delta C^{o b s}$ & $\Delta I^{o b s}$ & $H^{o b s}$ & $\Delta W^{o b s}$ & $\pi^{o b s}$ & $R^{o b s}$ \\
\hline \multirow[t]{6}{*}{ Technology } & $\varepsilon_{t}^{a}$ & 4.39 & 4.71 & 1.93 & 3.45 & 0.12 & 0.81 & 2.72 \\
\hline & $\eta_{t-1}^{a}$ & 0 & 0 & 0 & 0 & 0 & 0 & 0 \\
\hline & $\eta_{t-2}^{a}$ & 0.17 & 0.49 & 0.05 & 0.07 & 0 & 0.03 & 0.06 \\
\hline & $\eta_{t-3}^{a}$ & 0 & 0.01 & 0 & 0 & 0 & 0 & 0 \\
\hline & $\eta_{t-4}^{a}$ & 0.31 & 0.94 & 0.11 & 0.23 & 0.01 & 0.09 & 0.18 \\
\hline & $\eta_{t-5}^{a}$ & 0.24 & 0.74 & 0.10 & 0.23 & 0.01 & 0.09 & 0.19 \\
\hline \multirow[t]{6}{*}{ Risk-Premium } & $\varepsilon_{t}^{b}$ & 12.42 & 30.79 & 3.30 & 7.69 & 0.58 & 1.30 & 19.27 \\
\hline & $\eta_{t-1}^{b}$ & 0.13 & 0.31 & 0.04 & 0.09 & 0.01 & 0.02 & 0.24 \\
\hline & $\eta_{t-2}^{b}$ & 0.58 & 1.23 & 0.19 & 0.48 & 0.04 & 0.09 & 1.22 \\
\hline & $\eta_{t-3}^{b}$ & 0.93 & 1.83 & 0.35 & 0.90 & 0.07 & 0.18 & 2.38 \\
\hline & $\eta_{t-4}^{b}$ & 6.23 & 11.57 & 2.53 & 7.05 & 0.59 & 1.58 & 19.24 \\
\hline & $\eta_{t-5}^{b}$ & 6.55 & 11.67 & 2.85 & 8.59 & 0.75 & 2.21 & 24.36 \\
\hline \multirow[t]{6}{*}{ Govt. Spending } & $\varepsilon_{t}^{g}$ & 15.78 & 5.13 & 0.03 & 11.03 & 0.01 & 0.64 & 0.70 \\
\hline & $\eta_{t-1}^{g}$ & 0.70 & 0.31 & 0 & 0.28 & 0 & 0.02 & 0.02 \\
\hline & $\eta_{t-2}^{g}$ & 0.06 & 0.02 & 0 & 0.02 & 0 & 0 & 0 \\
\hline & $\eta_{t-3}^{g}$ & 0.27 & 0.10 & 0 & 0.10 & 0 & 0.01 & 0.01 \\
\hline & $\eta_{t-4}^{g}$ & 0.01 & 0 & 0 & 0 & 0 & 0 & 0 \\
\hline & $\eta_{t-5}^{g}$ & 0.03 & 0.01 & 0 & 0.01 & 0 & 0 & 0 \\
\hline \multirow[t]{6}{*}{ Investment-Specific Tech. } & $\varepsilon_{t}^{\phi}$ & 40.71 & 8.89 & 83.13 & 50.60 & 1.93 & 15.37 & 22.68 \\
\hline & $\eta_{t-1}^{\phi}$ & 0.27 & 0.08 & 0.54 & 0.37 & 0.01 & 0.11 & 0.17 \\
\hline & $\eta_{t-2}^{\phi}$ & 0.13 & 0.04 & 0.24 & 0.19 & 0.01 & 0.05 & 0.09 \\
\hline & $\eta_{t-3}^{\phi}$ & 0.16 & 0.06 & 0.29 & 0.24 & 0.01 & 0.07 & 0.11 \\
\hline & $\eta_{t-4}^{\phi}$ & 0.01 & 0 & 0.02 & 0.02 & 0 & 0 & 0.01 \\
\hline & $\eta_{t-5}^{\phi}$ & 0.35 & 0.12 & 0.60 & 0.45 & 0.02 & 0.12 & 0.21 \\
\hline \multirow[t]{6}{*}{ Price Markup } & $\varepsilon_{t}^{p}$ & 0.33 & 0.40 & 0.13 & 0.15 & 5.09 & 40.13 & 0.09 \\
\hline & $\eta_{t-1}^{p}$ & 0 & 0.01 & 0 & 0 & 0.03 & 0.35 & 0 \\
\hline & $\eta_{t-2}^{p}$ & 0.01 & 0.01 & 0 & 0 & 0.02 & 0.34 & 0 \\
\hline & $\eta_{t-3}^{p}$ & 0.01 & 0.02 & 0 & 0 & 0.02 & 0.38 & 0 \\
\hline & $\eta_{t-4}^{p}$ & 0 & 0 & 0 & 0 & 0 & 0.03 & 0 \\
\hline & $\eta_{t-5}^{p}$ & 0.12 & 0.24 & 0.04 & 0.06 & 0.17 & 4.52 & 0.05 \\
\hline \multirow[t]{6}{*}{ Wage Markup } & $\varepsilon_{t}^{w}$ & 0.30 & 0.41 & 0.23 & 0.71 & 59.22 & 9.06 & 0.87 \\
\hline & $\eta_{t-1}^{w}$ & 0.01 & 0.01 & 0.01 & 0.02 & 0.89 & 0.23 & 0.02 \\
\hline & $\eta_{t-2}^{w}$ & 0.01 & 0.01 & 0.01 & 0.02 & 0.65 & 0.25 & 0.02 \\
\hline & $\eta_{t-3}^{w}$ & 0 & 0 & 0 & 0.01 & 0.13 & 0.07 & 0.01 \\
\hline & $\eta_{t-4}^{w}$ & 0.29 & 0.60 & 0.56 & 1.50 & 26.74 & 18.98 & 1.88 \\
\hline & $\eta_{t-5}^{w}$ & 0.03 & 0.07 & 0.07 & 0.18 & 2.52 & 2.27 & 0.23 \\
\hline \multirow[t]{6}{*}{ Monetary Policy } & $\varepsilon_{t}^{m p}$ & 6.29 & 15.12 & 1.77 & 3.33 & 0.21 & 0.36 & 2.06 \\
\hline & $\eta_{t-1}^{m p}$ & 0.03 & 0.07 & 0.01 & 0.02 & 0 & 0 & 0.01 \\
\hline & $\eta_{t-2}^{m p}$ & 1.17 & 2.32 & 0.43 & 0.85 & 0.06 & 0.10 & 0.36 \\
\hline & $\eta_{t-3}^{m p}$ & 0.27 & 0.48 & 0.11 & 0.23 & 0.02 & 0.03 & 0.10 \\
\hline & $\eta_{t-4}^{m p}$ & 0.15 & 0.25 & 0.07 & 0.15 & 0.01 & 0.02 & 0.08 \\
\hline & $\eta_{t-5}^{m p}$ & 0.56 & 0.91 & 0.27 & 0.67 & 0.05 & 0.10 & 0.37 \\
\hline Total UnANTICIPATED & & $80 \%$ & $65 \%$ & $91 \%$ & $77 \%$ & $67 \%$ & $68 \%$ & $48 \%$ \\
\hline Total News & & $20 \%$ & $35 \%$ & $9 \%$ & $23 \%$ & $33 \%$ & $32 \%$ & $52 \%$ \\
\hline
\end{tabular}

Table 4 - Forecast Error Variance Decomposition. Smets and Wouters Model with news shocks. 


\begin{tabular}{|c|c|c|c|c|c|c|c|c|c|}
\hline & & $\Delta Y^{o b s}$ & $\Delta C^{o b s}$ & $\Delta I^{o b s}$ & $\Delta G^{o b s}$ & $H^{o b s}$ & $\Delta W^{o b s}$ & $\pi^{o b s}$ & $R^{o b s}$ \\
\hline \multirow[t]{6}{*}{ Technology } & $\varepsilon_{t}^{a}$ & 8.17 & 16.47 & 5.06 & 2.56 & 4.12 & 0.30 & 0.32 & 1.93 \\
\hline & $\eta_{t-1}^{a}$ & 0.79 & 1.84 & 0.29 & 0.17 & 0.27 & 0.02 & 0.02 & 0.10 \\
\hline & $\eta_{t-2}^{a}$ & 0.56 & 1.37 & 0.18 & 0.13 & 0.24 & 0.01 & 0.02 & 0.08 \\
\hline & $\eta_{t-3}^{a}$ & 0.03 & 0.06 & 0.01 & 0.01 & 0.01 & 0 & 0 & 0 \\
\hline & $\eta_{t-4}^{a}$ & 0.07 & 0.19 & 0.02 & 0.02 & 0.05 & 0 & 0 & 0.02 \\
\hline & $\eta_{t-5}^{a}$ & 1.60 & 4.49 & 0.71 & 0.70 & 1.56 & 0.08 & 0.10 & 0.61 \\
\hline \multirow[t]{6}{*}{ Risk-Premium } & $\varepsilon_{t}^{b}$ & 0.12 & 0.22 & 0.04 & 0 & 0.08 & 0 & 0.09 & 0.88 \\
\hline & $\eta_{t-1}^{b}$ & 5.04 & 9.01 & 1.72 & 0 & 3.85 & 0.17 & 4.13 & 42.29 \\
\hline & $\eta_{t-2}^{b}$ & 0.01 & 0.03 & 0.01 & 0 & 0.01 & 0 & 0.01 & 0.15 \\
\hline & $\eta_{t-3}^{b}$ & 1.87 & 3.06 & 0.73 & 0 & 1.92 & 0.09 & 2.20 & 22.23 \\
\hline & $\eta_{t-4}^{b}$ & 0.67 & 1.07 & 0.27 & 0 & 0.81 & 0.04 & 0.98 & 9.80 \\
\hline & $\eta_{t-5}^{b}$ & 0.30 & 0.48 & 0.12 & 0 & 0.43 & 0.02 & 0.55 & 5.43 \\
\hline \multirow[t]{6}{*}{ Govt. Spending } & $\varepsilon_{t}^{g}$ & 3.08 & 0.77 & 0.07 & 83.57 & 1.74 & 0 & 0.01 & 0.10 \\
\hline & $\eta_{t-1}^{g}$ & 0.09 & 0.03 & 0 & 1.45 & 0.03 & 0 & 0 & 0 \\
\hline & $\eta_{t-2}^{g}$ & 0.75 & 0.26 & 0 & 10.39 & 0.23 & 0 & 0 & 0.01 \\
\hline & $\eta_{t-3}^{g}$ & 0.01 & 0 & 0 & 0.17 & 0 & 0 & 0 & 0 \\
\hline & $\eta_{t-4}^{g}$ & 0.05 & 0.01 & 0 & 0.62 & 0.01 & 0 & 0 & 0 \\
\hline & $\eta_{t-5}^{g}$ & 0.02 & 0 & 0 & 0.22 & 0 & 0 & 0 & 0 \\
\hline \multirow[t]{6}{*}{ Investment-Specific Tech. } & $\varepsilon_{t}^{\phi}$ & 20.67 & 1.22 & 53.25 & 0 & 12.03 & 0.06 & 0.06 & 5.36 \\
\hline & $\eta_{t-1}^{\phi}$ & 0.05 & 0.01 & 0.12 & 0 & 0.03 & 0 & 0 & 0.01 \\
\hline & $\eta_{t-2}^{\phi}$ & 0 & 0 & 0.01 & 0 & 0 & 0 & 0 & 0 \\
\hline & $\eta_{t-3}^{\phi}$ & 0.17 & 0.04 & 0.36 & 0 & 0.12 & 0 & 0 & 0.06 \\
\hline & $\eta_{t-4}^{\phi}$ & 0.12 & 0.03 & 0.23 & 0 & 0.08 & 0 & 0 & 0.04 \\
\hline & $\eta_{t-5}^{\phi}$ & 0.06 & 0.01 & 0.11 & 0 & 0.04 & 0 & 0 & 0.02 \\
\hline \multirow[t]{6}{*}{ Price Markup } & $\varepsilon_{t}^{p}$ & 0.63 & 0.30 & 0.28 & 0 & 0.13 & 3.67 & 51.99 & 0.33 \\
\hline & $\eta_{t-1}^{p}$ & 0.02 & 0.02 & 0.01 & 0 & 0 & 0.04 & 0.87 & 0.01 \\
\hline & $\eta_{t-2}^{p}$ & 0.12 & 0.16 & 0.05 & 0 & 0.03 & 0.21 & 5.11 & 0.06 \\
\hline & $\eta_{t-3}^{p}$ & 0.15 & 0.21 & 0.06 & 0 & 0.03 & 0.19 & 5.08 & 0.08 \\
\hline & $\eta_{t-4}^{p}$ & 0.03 & 0.05 & 0.01 & 0 & 0.01 & 0.03 & 0.94 & 0.02 \\
\hline & $\eta_{t-5}^{p}$ & 0.91 & 1.29 & 0.37 & 0 & 0.23 & 0.74 & 23.78 & 0.59 \\
\hline \multirow[t]{6}{*}{ Wage Markup } & $\varepsilon_{t}^{w}$ & 0.99 & 2.31 & 0.04 & 0 & 3.70 & 83.46 & 2.21 & 0.69 \\
\hline & $\eta_{t-1}^{w}$ & 0 & 0.01 & 0 & 0 & 0.03 & 0.37 & 0.02 & 0.01 \\
\hline & $\eta_{t-2}^{w}$ & 0.04 & 0.18 & 0.01 & 0 & 0.40 & 3.76 & 0.27 & 0.08 \\
\hline & $\eta_{t-3}^{w}$ & 0 & 0 & 0 & 0 & 0 & 0.01 & 0 & 0 \\
\hline & $\eta_{t-4}^{w}$ & 0 & 0.01 & 0 & 0 & 0.02 & 0.09 & 0.01 & 0 \\
\hline & $\eta_{t-5}^{w}$ & 0.05 & 0.32 & 0.03 & 0 & 0.99 & 4.73 & 0.77 & 0.20 \\
\hline \multirow[t]{6}{*}{ Monetary Policy } & $\varepsilon_{t}^{m p}$ & 2.10 & 2.70 & 1.16 & 0 & 1.52 & 0.03 & 0 & 0.31 \\
\hline & $\eta_{t-1}^{m p}$ & 0.03 & 0.03 & 0.02 & 0 & 0.02 & 0 & 0 & 0 \\
\hline & $\eta_{t-2}^{m p}$ & 22.27 & 24.49 & 14.12 & 0 & 22.15 & 0.54 & 0.09 & 2.35 \\
\hline & $\eta_{t-3}^{m p}$ & 3.84 & 3.95 & 2.58 & 0 & 4.51 & 0.12 & 0.02 & 0.49 \\
\hline & $\eta_{t-4}^{m p}$ & 2.74 & 2.68 & 1.93 & 0 & 3.78 & 0.11 & 0.02 & 0.48 \\
\hline & $\eta_{t-5}^{m p}$ & 21.83 & 20.58 & 16.06 & 0 & 34.76 & 1.07 & 0.29 & 5.20 \\
\hline TOTAL UNANTICIPATED & & $36 \%$ & $24 \%$ & $60 \%$ & $86 \%$ & $23 \%$ & $88 \%$ & $55 \%$ & $10 \%$ \\
\hline Total News & & $64 \%$ & $76 \%$ & $40 \%$ & $14 \%$ & $77 \%$ & $12 \%$ & $45 \%$ & $90 \%$ \\
\hline
\end{tabular}

Table 5 - Forecast Error Variance Decomposition. Model with real-time data and news shocks. 


\begin{tabular}{|c|c|c|c|c|c|c|c|c|c|}
\hline & & $\Delta Y^{o b s}$ & $\Delta C^{o b s}$ & $\Delta I^{o b s}$ & $\Delta G^{o b s}$ & $H^{o b s}$ & $\Delta W^{o b s}$ & $\pi^{o b s}$ & $R^{o b s}$ \\
\hline \multirow[t]{6}{*}{ Technology } & $\varepsilon_{t}^{a}$ & 1.64 & 2.38 & 0.83 & 1.93 & 0.80 & 0.24 & 1.28 & 1.92 \\
\hline & $\eta_{t-1}^{a}$ & 0.38 & 1.67 & 0.05 & 0.15 & 0.06 & 0.02 & 0.11 & 0.15 \\
\hline & $\eta_{t-2}^{a}$ & 0.13 & 0.64 & 0.01 & 0.05 & 0.03 & 0.01 & 0.04 & 0.05 \\
\hline & $\eta_{t-3}^{a}$ & 0.14 & 0.76 & 0.02 & 0.06 & 0.04 & 0.01 & 0.06 & 0.07 \\
\hline & $\eta_{t-4}^{a}$ & 0.07 & 0.41 & 0.01 & 0.04 & 0.03 & 0 & 0.04 & 0.04 \\
\hline & $\eta_{t-5}^{a}$ & 0 & 0 & 0 & 0 & 0 & 0 & 0 & 0 \\
\hline \multirow[t]{6}{*}{ Risk-Premium } & $\varepsilon_{t}^{b}$ & 7.05 & 11.61 & 4.05 & 0 & 2.61 & 0.81 & 1.08 & 7.23 \\
\hline & $\eta_{t-1}^{b}$ & 0.11 & 0.18 & 0.07 & 0 & 0.04 & 0.01 & 0.02 & 0.12 \\
\hline & $\eta_{t-2}^{b}$ & 0.10 & 0.14 & 0.06 & 0 & 0.04 & 0.01 & 0.02 & 0.11 \\
\hline & $\eta_{t-3}^{b}$ & 0.51 & 0.74 & 0.33 & 0 & 0.24 & 0.08 & 0.11 & 0.68 \\
\hline & $\eta_{t-4}^{b}$ & 0.35 & 0.50 & 0.23 & 0 & 0.18 & 0.06 & 0.09 & 0.53 \\
\hline & $\eta_{t-5}^{b}$ & 7.68 & 10.74 & 5.22 & 0 & 4.42 & 1.47 & 2.51 & 13.59 \\
\hline \multirow[t]{6}{*}{ Govt. Spending } & $\varepsilon_{t}^{g}$ & 0.77 & 0.21 & 0.01 & 82.17 & 0.48 & 0 & 0.06 & 0.14 \\
\hline & $\eta_{t-1}^{g}$ & 0.19 & 0.19 & 0 & 7.61 & 0.05 & 0 & 0.01 & 0.01 \\
\hline & $\eta_{t-2}^{g-1}$ & 0.05 & 0.05 & 0 & 1.63 & 0.01 & 0 & 0 & 0 \\
\hline & $\eta_{t-3}^{g}$ & 0.03 & 0.03 & 0 & 1.26 & 0.01 & 0 & 0 & 0 \\
\hline & $\eta_{t-4}^{g}$ & 0.04 & 0.03 & 0 & 1.35 & 0.01 & 0 & 0 & 0 \\
\hline & $\eta_{t-5}^{g}$ & 0.09 & 0.08 & 0.01 & 3.68 & 0.02 & 0 & 0 & 0.01 \\
\hline \multirow[t]{6}{*}{ Investment-Specific Tech. } & $\varepsilon_{t}^{\phi}$ & 36.82 & 23.81 & 45.70 & 0 & 57.67 & 5.52 & 22.75 & 48.82 \\
\hline & $\eta_{t-1}^{\phi}$ & 9.67 & 5.84 & 12.61 & 0 & 17.52 & 1.63 & 7.31 & 15.15 \\
\hline & $\eta_{t-2}^{\phi}$ & 0.75 & 0.40 & 1.06 & 0 & 1.18 & 0.10 & 0.54 & 1.04 \\
\hline & $\eta_{t-3}^{\phi}$ & 0.89 & 0.44 & 1.30 & 0 & 1.01 & 0.08 & 0.50 & 0.90 \\
\hline & $\eta_{t-4}^{\phi}$ & 1.10 & 0.54 & 1.61 & 0 & 0.94 & 0.07 & 0.50 & 0.84 \\
\hline & $\eta_{t-5}^{\phi}$ & 1.38 & 0.69 & 2.02 & 0 & 0.99 & 0.08 & 0.56 & 0.88 \\
\hline \multirow[t]{6}{*}{ Price Markup } & $\varepsilon_{t}^{p}$ & 0.08 & 0.09 & 0.06 & 0 & 0.02 & 0.94 & 12.40 & 0.01 \\
\hline & $\eta_{t-1}^{p}$ & 0.03 & 0.05 & 0.02 & 0 & 0.01 & 0.12 & 2.11 & 0 \\
\hline & $\eta_{t-2}^{p}$ & 0.06 & 0.12 & 0.03 & 0 & 0.01 & 0.13 & 2.61 & 0 \\
\hline & $\eta_{t-3}^{p}$ & 0.15 & 0.32 & 0.07 & 0 & 0.03 & 0.21 & 4.71 & 0.01 \\
\hline & $\eta_{t-4}^{p}$ & 0.11 & 0.23 & 0.05 & 0 & 0.02 & 0.11 & 2.61 & 0.01 \\
\hline & $\eta_{t-5}^{p-4}$ & 0.11 & 0.22 & 0.05 & 0 & 0.02 & 0.07 & 1.94 & 0.01 \\
\hline \multirow[t]{6}{*}{ Wage Markup } & $\varepsilon_{t}^{w}$ & 4.23 & 2.00 & 5.38 & 0 & 1.41 & 61.15 & 14.29 & 1.74 \\
\hline & $\eta_{t-1}^{w}$ & 0 & 0 & 0.01 & 0 & 0 & 0.05 & 0.01 & 0 \\
\hline & $\eta_{t-2}^{w}$ & 0.02 & 0.01 & 0.03 & 0 & 0.01 & 0.16 & 0.06 & 0.01 \\
\hline & $\eta_{t-3}^{w}$ & 0.01 & 0.01 & 0.01 & 0 & 0 & 0.07 & 0.03 & 0 \\
\hline & $\eta_{t-4}^{w}$ & 0.01 & 0 & 0.01 & 0 & 0 & 0.04 & 0.02 & 0 \\
\hline & $\eta_{t-5}^{w}$ & 5.87 & 3.10 & 7.79 & 0 & 2.50 & 24.36 & 18.22 & 2.93 \\
\hline \multirow[t]{6}{*}{ Monetary Policy } & $\varepsilon_{t}^{m p}$ & 13.46 & 22.17 & 7.73 & 0 & 5.06 & 1.59 & 2.15 & 1.92 \\
\hline & $\eta_{t-1}^{m p}$ & 3.83 & 6.06 & 2.28 & 0 & 1.52 & 0.48 & 0.66 & 0.50 \\
\hline & $\eta_{t-2}^{m p}$ & 0.98 & 1.49 & 0.61 & 0 & 0.42 & 0.13 & 0.19 & 0.16 \\
\hline & $\eta_{t-3}^{m p}$ & 0.36 & 0.53 & 0.23 & 0 & 0.17 & 0.05 & 0.08 & 0.08 \\
\hline & $\eta_{t-4}^{m p}$ & 0.33 & 0.47 & 0.22 & 0 & 0.17 & 0.06 & 0.09 & 0.10 \\
\hline & $\eta_{t-5}^{m p}$ & 0.34 & 0.48 & 0.23 & 0 & 0.20 & 0.07 & 0.12 & 0.14 \\
\hline Total Unanticipated & & $64 \%$ & $62 \%$ & $64 \%$ & $84 \%$ & $68 \%$ & $70 \%$ & $54 \%$ & $62 \%$ \\
\hline Total News & & $36 \%$ & $38 \%$ & $36 \%$ & $16 \%$ & $32 \%$ & $30 \%$ & $46 \%$ & $38 \%$ \\
\hline
\end{tabular}

Table 6 - Forecast Error Variance Decomposition. Baseline model with real-time data, observed expectations, and news shocks. 
SW data \& Expectations Linear Trend Flex Prices/Wages Smaller M.E.

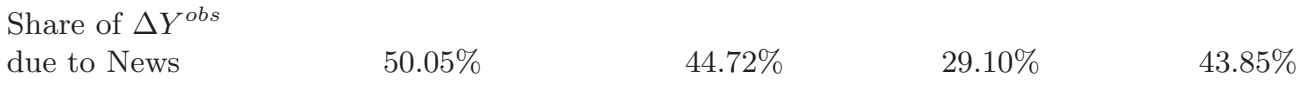

Table 7 - Forecast Error Variance Decomposition. Robustness across models, data sets, and estimation choices. Note: the table presents the forecast error variance of real output growth due to the sum of all news shocks. The first value refers to the baseline estimation repeated with revised, rather than real-time, data, the second to the estimation with variable-specific linear trends, rather than a common trend restriction across real variables, the third to the nested model with flexible prices and no indexation, and the fourth to the estimation with measurement errors restricted to have a variance lower than $10 \%$ of the variance of the variable they refer to. 

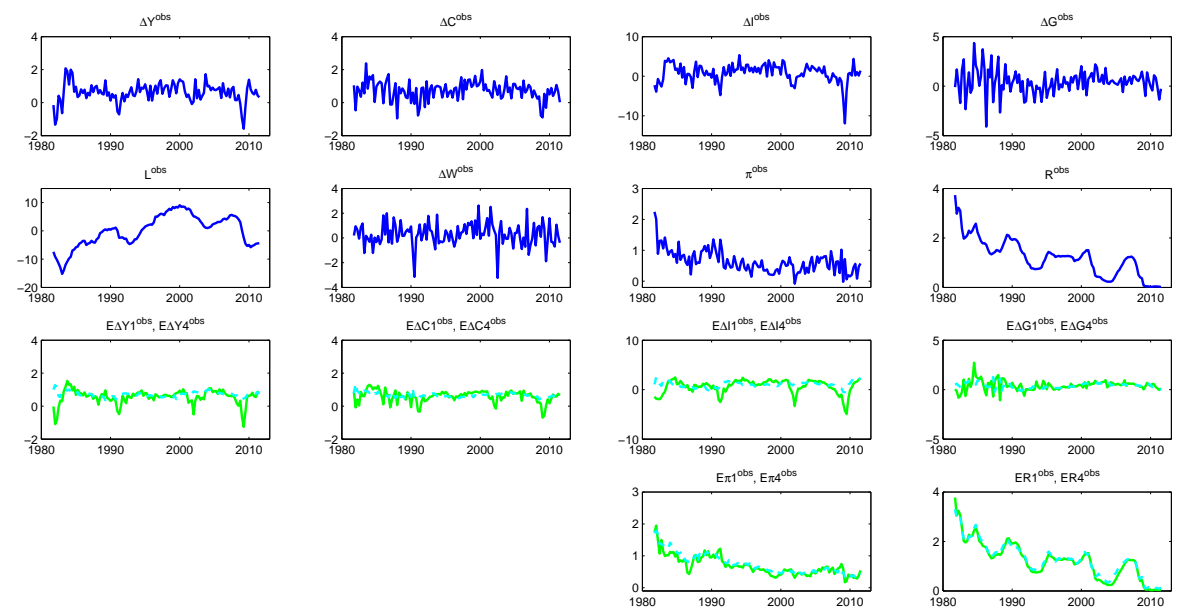

FiguRE 1. Observed data series: realized variables (top half) and selected expectations series (bottom half); only one-period-ahead (solid line) and four-period-ahead (dashed line) expectations are shown to maintain clarity in the graph (two-, three-, and five-period-ahead expectations are also included in the estimation). 


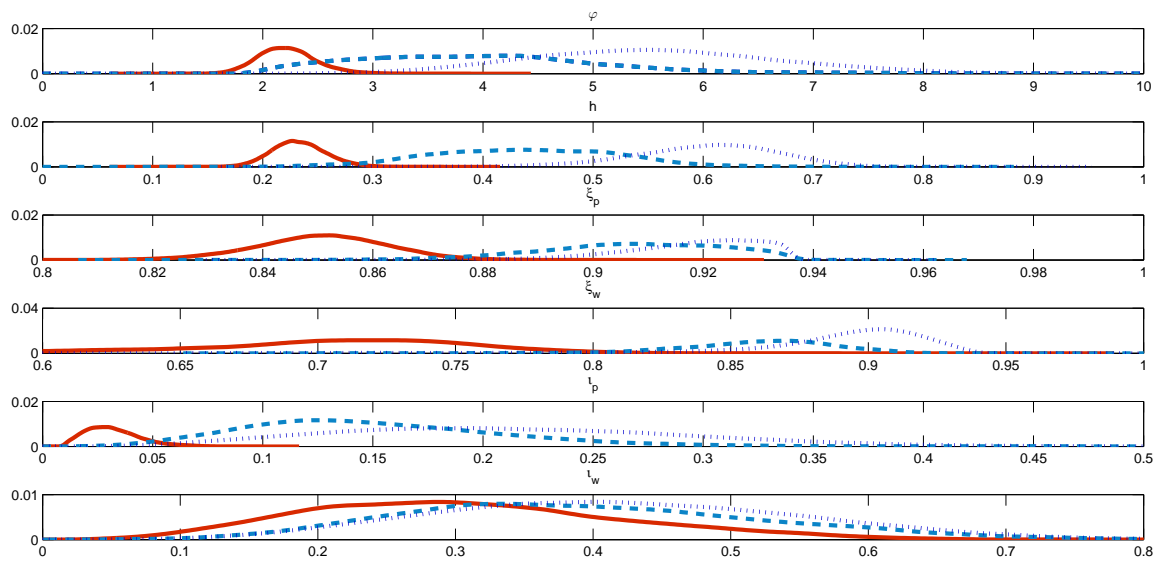

Figure 2. Posterior distributions for real and nominal frictions coefficients, across estimated specifications. From top to bottom, the graph shows the distributions for the investment adjustment cost, habit formation, price stickiness, wage stickiness, price indexation, wage indexation, coefficients. The distributions are compared across estimations with real-time data and no news (dotted), real-time data and news shocks (dashed), and real-time data, news, and expectations data (solid). 

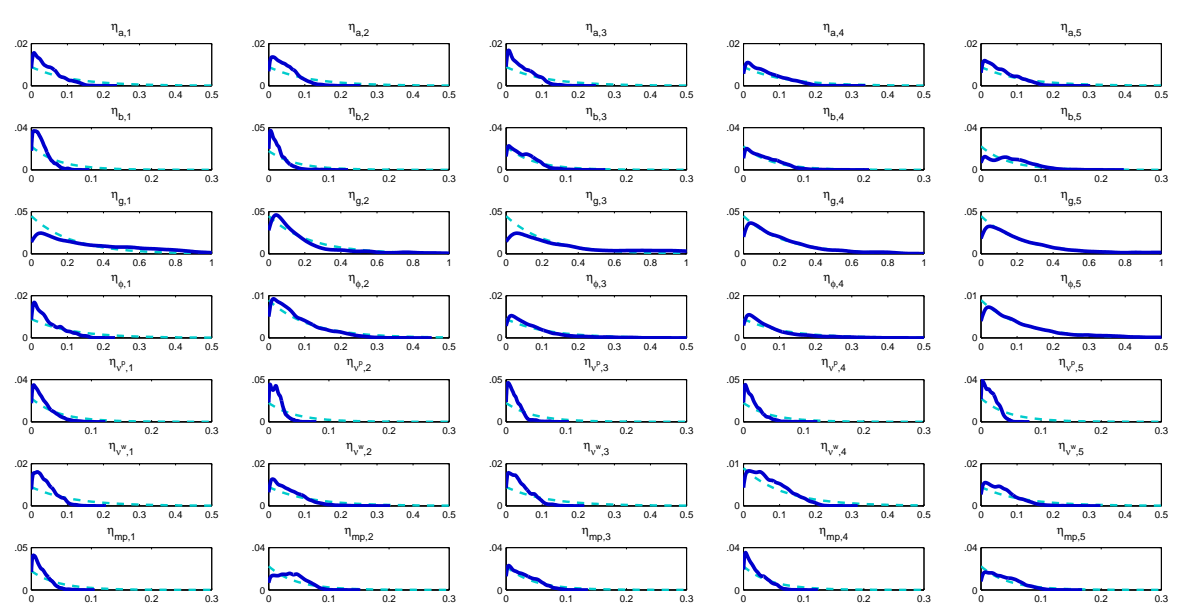

FiguRE 3. Standard deviation coefficients for news shocks: prior (dashed) and posterior (solid) distributions for estimated model with Smets and Wouters' (2007) revised data and without observed expectations. From top to bottom, and from left to right, the graph shows the results for news about technology, risk premium, government spending, investment-specific, price and wage markup, and monetary policy disturbances, at horizons from one quarter to five quarters ahead. 

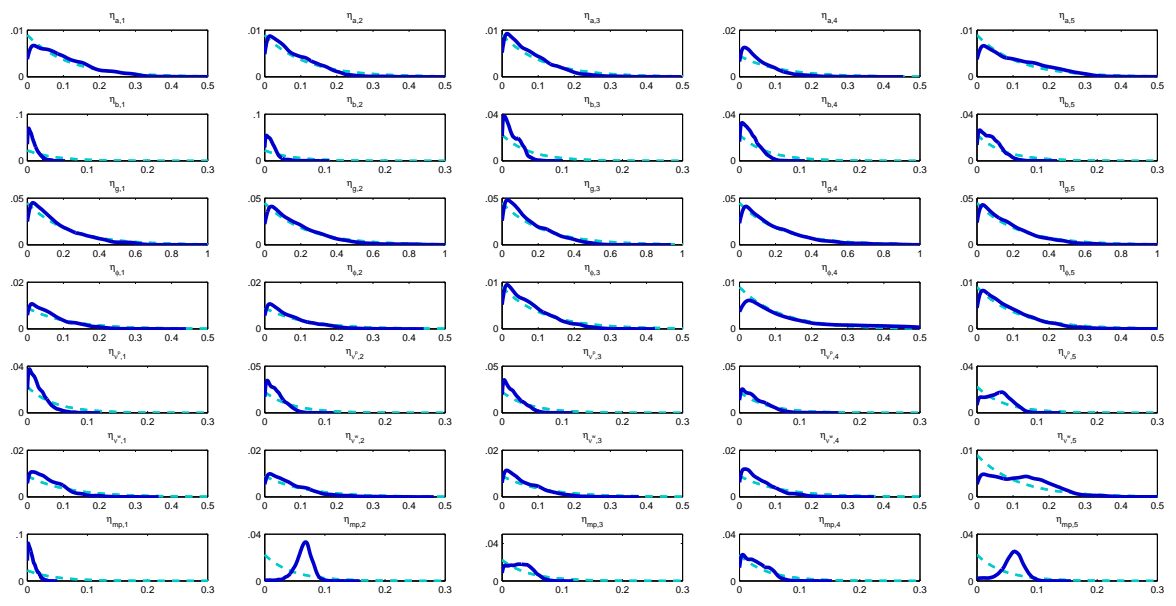

FiguRE 4. Standard deviation coefficients for news shocks: prior (dashed) and posterior (solid) distributions for estimated model with real-time data, but without observed expectations. From top to bottom, and from left to right, the graph shows the results for news about technology, risk premium, government spending, investment-specific, price and wage markup, and monetary policy disturbances, at horizons from one quarter to five quarters ahead. 

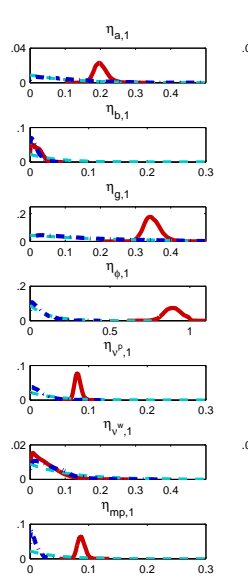
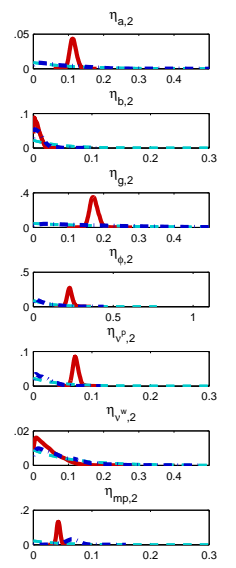
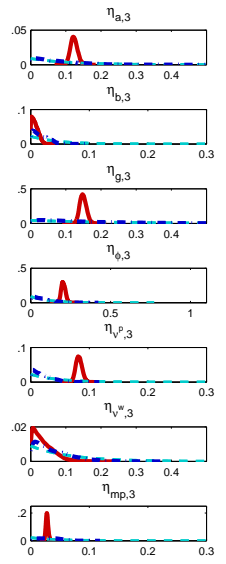
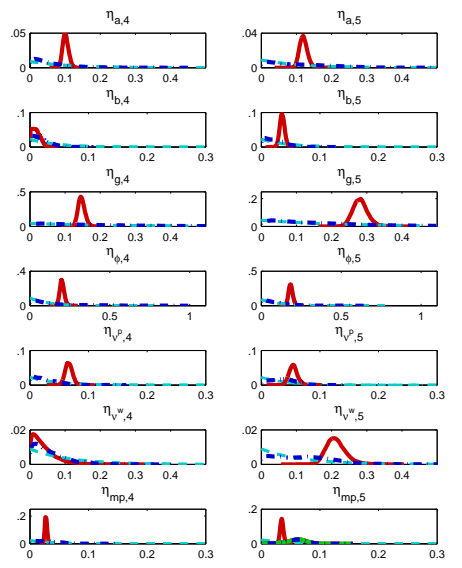

FIGURE 5. Standard deviation coefficients for news shocks: prior and posterior distributions for estimated models with and without expectations data. The solid red line indicates the posterior distribution for the estimated model with real-time data and survey expectations as observables; the dashed blue line indicates the posterior distribution for the estimated model with real-time data, but without expectations data; the dashed celeste line indicates the corresponding prior distributions, identical across the two estimated models. From top to bottom, and from left to right, the graph shows the results for news about technology, risk premium, government spending, investment-specific, price and wage markup, and monetary policy disturbances, at horizons from one quarter to five quarters ahead. 

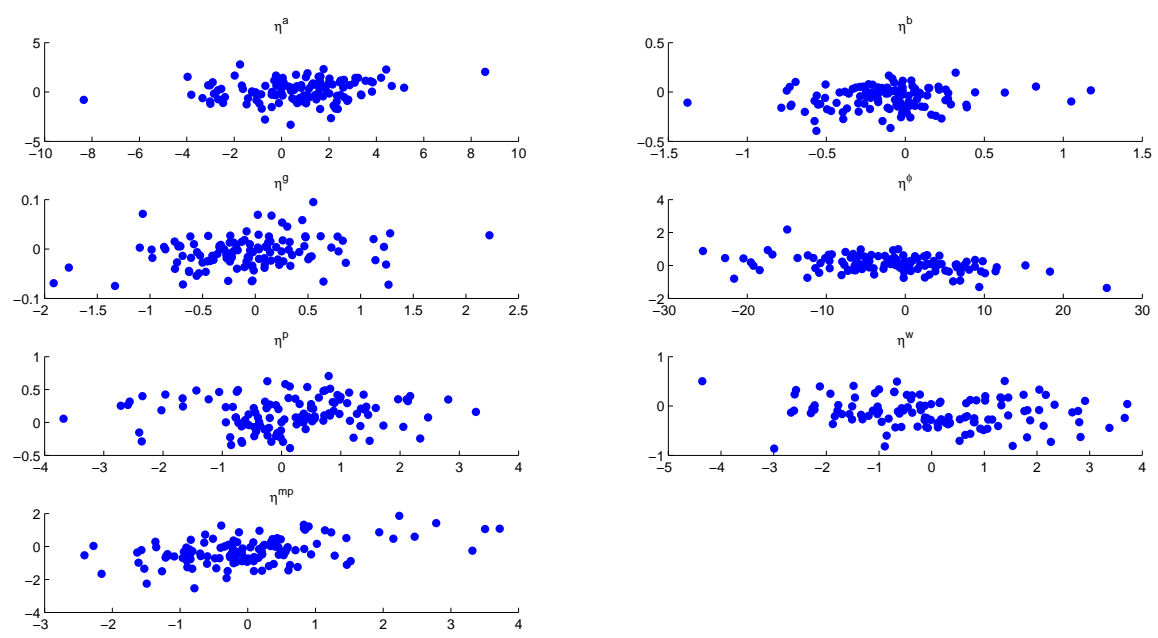

FiguRE 6. News shocks correlation across estimation scenarios. The graph shows scatter plots between news shocks extracted from the estimation without expectations data and the corresponding news shocks for the baseline estimation with expectations data. For each disturbance, the graph considers the sum of news shocks over different horizons. News corresponds to the posterior mean across draws, smoothed series. 